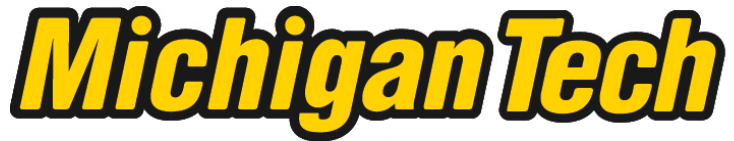 \\ Michigan Technological University Create the Future Digital Commons @ Michigan Tech
}

Dissertations, Master's Theses and Master's Reports - Open

Dissertations, Master's Theses and Master's

Reports

2006

Effects of carbonation on the mineral composition of cement kiln dust

Cecilia P. Anderson

Michigan Technological University

Follow this and additional works at: https://digitalcommons.mtu.edu/etds

Part of the Geology Commons

Copyright 2006 Cecilia P. Anderson

\section{Recommended Citation}

Anderson, Cecilia P., "Effects of carbonation on the mineral composition of cement kiln dust", Master's Thesis, Michigan Technological University, 2006.

https://doi.org/10.37099/mtu.dc.etds/310

Follow this and additional works at: https://digitalcommons.mtu.edu/etds

Part of the Geology Commons 


\title{
EFFECTS OF CARBONATION ON THE MINERAL COMPOSITION OF CEMENT KILN Dust
}

\author{
By \\ CeCilia P. ANDERson
}

\author{
A Thesis \\ Submitted in partial fulfillment of the requirements \\ for the degree of \\ MASTER OF SCIENCE IN GEOLOGY
}

MICHIGAN TECHNOLOGICAL UNIVERSITY

2006 
This thesis, "EFFects of CARbonation on the Mineral Composition of CEMENT KiLN DusT," is hereby approved in partial fulfillment of the requirements for the Degree of MASTER OF SCIENCE IN GEOLOGY.

DEPARTMENT of Geological and Mining Engineering and Sciences

Signatures:

Thesis Advisor: $\quad$ Dr. John S. Gierke

Department Chair: Dr. Wayne D. Pennington

Date: 10/03/06 


\title{
Michigan Technological University
}

\section{AbSTRACT \\ EFFECTS OF CARBONATION ON THE MineRAL COMPOSITION OF CEMENT KILN Dust}

\author{
By Cecilia P. Anderson \\ Department of Geological \& Mining Engineering \& Sciences
}

3 October 2006

Due to their relatively high calcium oxide content, industrial mineral oxide wastes are potential candidates for mineral sequestration of carbon dioxide $\left(\mathrm{CO}_{2}\right)$. Cement kiln dust (CKD), a byproduct of cement manufacturing contains $20-60 \% \mathrm{CaO}$ making it a possible candidate for $\mathrm{CO}_{2}$ sequestration. In this study, three types of $\mathrm{CKD}$ are characterized, before and after carbonation, using environmental scanning electron microscopy and energy dispersive $\mathrm{x}$-ray microanalysis to determine the mineralogical and morphological changes occurring due to carbonation. The reactants, products, and precipitation mechanisms were investigated to enhance understanding of the governing processes and allow better utilization of $\mathrm{CKD}$ for $\mathrm{CO}_{2}$ sequestration. The results of multiple independent analyses confirmed the formation of $\mathrm{CaCO}_{3}$ during carbonation. Examinations of the reaction pathways found that $\mathrm{CaO}$ and calcium hydroxide $\left(\mathrm{Ca}(\mathrm{OH})_{2}\right)$ were the major reactants. Three types of $\mathrm{CaCO}_{3}$ precipitation mechanisms were observed: (1) diffusion of $\mathrm{CO}_{2}$ into $\mathrm{Ca}(\mathrm{OH})_{2}$ particles causing precipitation in the pores of the particle and the growth of $\mathrm{CaCO}_{3}$ ring from the outside inward, (2) precipitation onto existing particles, and (3) precipitation from aqueous solution. The growth of a $\mathrm{CaCO}_{3}$ ring on the outside of a particle may slow further diffusion of $\mathrm{CO}_{2}$ into a particle slowing 
the overall sequestration rate. Additionally, changes caused by carbonation in the solubility of trace metals were studied by mixing pre- and post-carbonated CKD with water and analyzing the solution using inductively coupled plasma mass spectrometry. Decreases in the leaching of chromium, lead, and copper were observed, and is an incentive for use of $\mathrm{CKD}$ for $\mathrm{CO}_{2}$ sequestration. Equilibrium modeling using PHREEQC confirmed that $\mathrm{CaO}$ and $\mathrm{Ca}(\mathrm{OH})_{2}$ would carbonate readily and form $\mathrm{CaCO}_{3}$. 


\section{Preface}

The following document has been formatted as an Electronic Thesis or Dissertation (ETD). Hyperlinks and bookmarks are intended to facilitate navigation from the table of contents and to section headings within the main document. After following a hyperlink, the reader may use the back button on the tool bar to return to the previous location in the document. The linked figures and tables are located at the end of the text document and are numbered sequentially. 


\section{ACKNOWLEDGEMENTS}

This research was funded in part by the Department of Geological and Mining Engineering and Sciences at Michigan Technological University, the Michigan Space Grant Consortium (MSGC) and the Institute of Hazardous Materials Management (IHMM).

I would like to thank my committee: Dr. Larry Sutter, Dr. Gregg Bluth, and Dr. Doug McDowell, for their time and input in my research. My gratitude also extends to Debbie Huntzinger for her excellent examples of research and writing and for providing me with several crash courses in carbonate chemistry.

Karl Peterson provided instruction and assistance on ESEM and EDX along with sample preparation and the carbon coating of countless samples. I would also like to thank Matt King, Owen Mills, and Bob Barron for their technical assistance. Additional thanks to Greg Barger at Ash Grove Cement Company, for providing the cement kiln dust samples and allowing us to tour the facilities in Kansas.

Endless appreciation goes to my thesis advisor, Dr. John Gierke, who provided the guidance needed to find my path through this program. By his example, I have improved my writing, teaching ability, and methods of research. Thanks to him, I have also enhanced my use of $\$ 5$ (and occasionally $\$ 10$ ) words. His mentorship has been invaluable to my present and future success as a scientist.

Finally, my completion of this degree would not have been possible without the support of my parents, husband, friends, and extended family. Their unwavering faith in my abilities has been there when I have needed it the most. 


\section{TABLE OF CONTENTS}

$\underline{\text { SECTION }} \quad \underline{\text { PAGE }}$

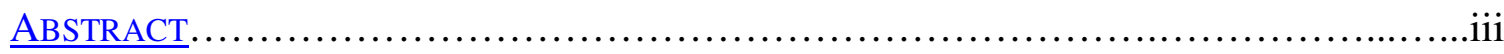

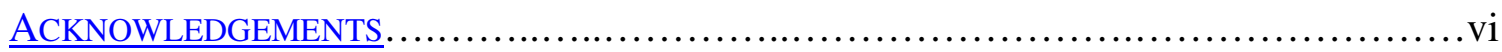

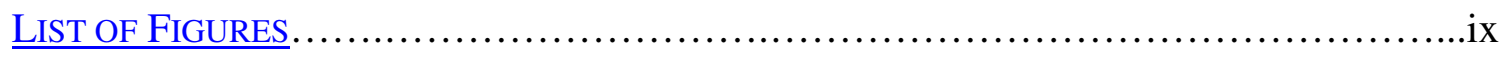

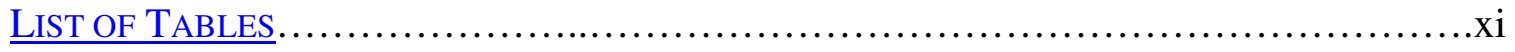

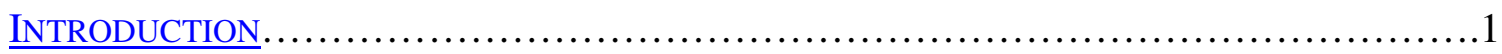

1.1. Carbonation Chemistry................................................4

1.2. Ancillary Effects of Carbonation......................................6

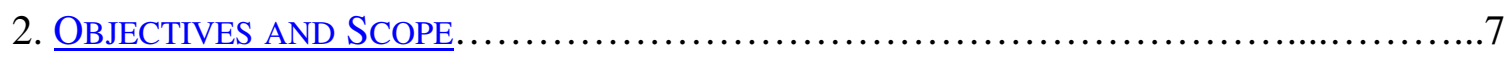

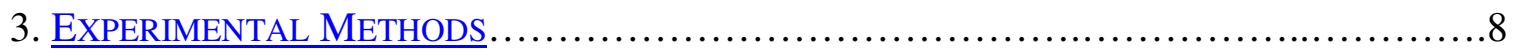

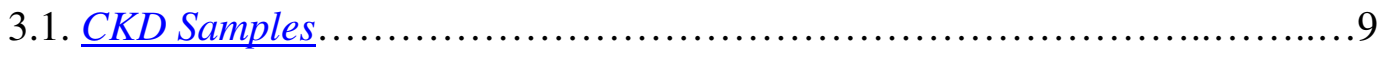

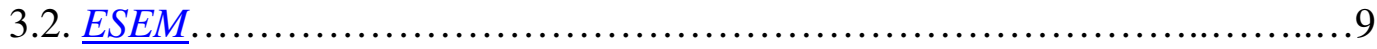

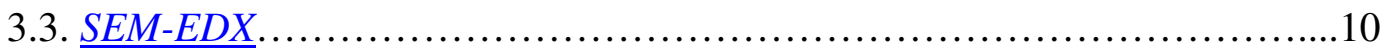

3.4. Thermodynamic Equilibrium Evaluations.............................11

3.4.1. Laboratory Analyses.....................................12

3.4.2. Geochemical Equilibrium Modeling.........................12

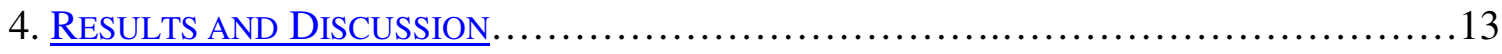

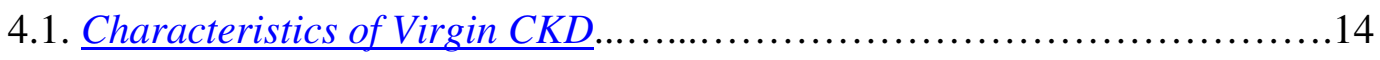

4.2. Reaction Participants and Products.................................. 15

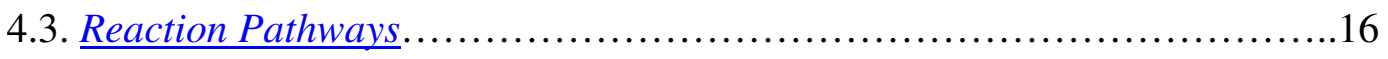

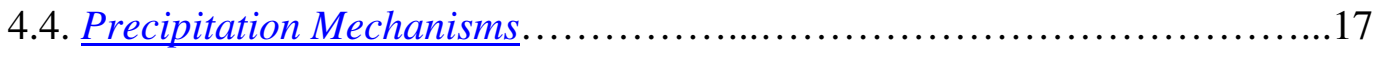

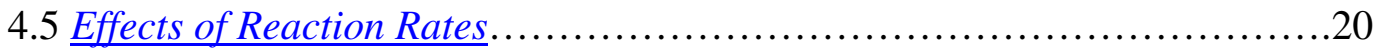




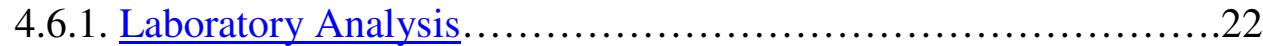

4.6.2. Geochemical Equilibrium Modeling............................23

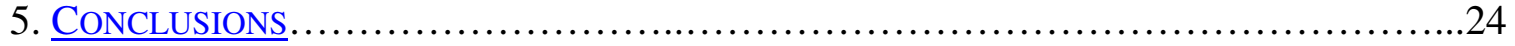

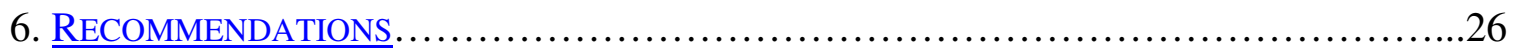

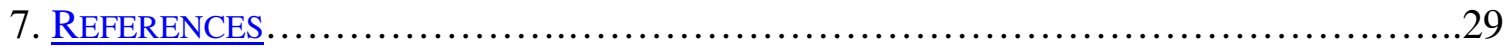

APPENDIX A: ESEM Stub Comparison.......................................CD-ROM

APPENDIX B: SEM-EDX Elemental Mapping .....................................

APPENDIX C: SEM-EDX Microanalysis Data....................................ROM

APPENDIX D: Additional SEM Images of CKD ...............................R-ROM

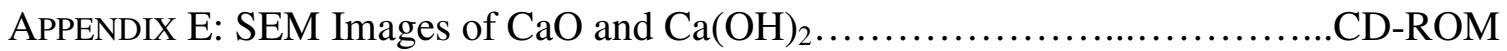




\section{LIST OF FigURES}

$\underline{\text { FIGURE }}$

$\underline{\text { PAGE }}$

Figure 1: The reaction box used to carbonate cement kiln dust samples was connected to a pure- $\mathrm{CO}_{2}$ tank. $\mathrm{CO}_{2}$ was first passed through distilled/deionized (DI) water prior to entering the box, which contained a pan of DI water and a humidity monitor. $\mathrm{CO}_{2}$ concentrations were monitored by twice-daily air samples run through a gas chromatograph.

Figure 2: Area mapped for the Virgin Ash Grove Bypass High showing the locations that were analyzed using energy dispersive $\mathrm{x}$-ray microanalysis. The energy dispersive $\mathrm{x}$-ray results are summarized in Table 3

Figure 3: Direct comparisons of an AG Bypass High cement kiln dust particle conducted by environmental scanning electron microscopy. The increased clarity of the image of the carbonated form is due to the precipitation of carbonates, which have higher density than oxides

Figure 4: Direct comparison of Ash Grove Bypass Low particle conducted by environmental scanning electron microscopy and showing the formation of sylvite $(\mathrm{KCl})$

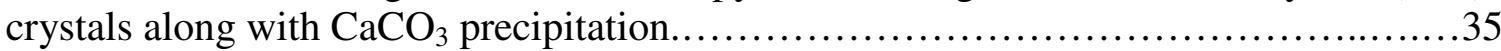

Figure 5: Direct comparison of Ash Grove Wet particle conducted by environmental scanning electron microscopy and showing the formation of fibrous calcite crystals along

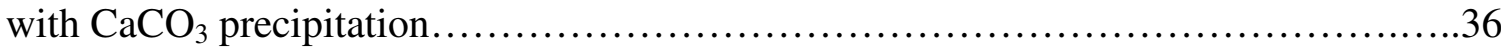

Figure 6: Backscattered electron images (left) and the results of calcium (Ca) mapping by energy dispersive $\mathrm{x}$-ray (right) on the AG Bypass High cement kiln dust. The bright white represent the highest calcium content and black represents the absence of Ca. Figures 6a-b are of virgin cement kiln dust, 6c-d are 8-hour reacted cement kiln dust, and 6e-f are 4-day reacted cement kiln dust. The $\mathrm{Ca}$ content, corresponding to the carbonation of free lime and portlandite, appears to increase over time. The highlighted particle in $6 \mathrm{f}$

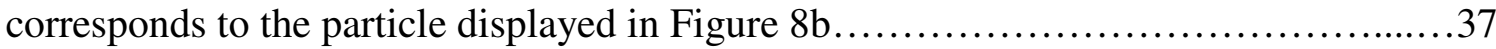

Figure 7: Ash Grove Bypass High Particle with depleted calcium silicate center and precipitate $\mathrm{CaCO}_{3}$ on the edge. Corresponding calcium $(\mathrm{Ca})$ and silicon $(\mathrm{Si})$ maps are shown with the zoomed particle outlined. The presence of $\mathrm{Si}$ is evident in the low $\mathrm{Ca}$ content center. The particle shows the average composition with standard deviations obtained from energy dispersive x-ray microanalysis for the center and edge of this

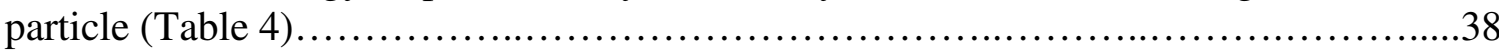

Figure 8: Backscatter electron images of particles of 4-day Ash Grove Bypass High exhibiting different degrees of carbonations: (a) particle with limited calcite (B) rim 
around portlandite (A) center, (b) particle with larger calcite (B) rim and smaller portlandite (A) center suggesting greater carbonation. Table 6 provides five detailed, elemental composition of labeled areas

Figure 9: Backscattered electron images of two examples of carbonate precipitation in 8hour and 4-day carbonated Ash Grove Bypass High. Both have calcium contents of 37\% (dry weight) and are similar in shape and color. Table 7 lists the energy dispersive x-ray elemental microanalysis data for these particles.

Figure 10: Backscattered electron (BSE) image of a particle of $\mathrm{CaCO}_{3}$ in 4-day carbonated samples of Ash Grove Wet. Particle composition (see Table 8) is $\mathrm{CaCO}_{3}$. The calcium (Ca) content map (lower) shows constant calcium content for this particle (see boxed area). The altered edge is mostly likely newly precipitated $\mathrm{CaCO}_{3}$, while the center was present in the virgin cement kiln dust and acted as a nucleus to precipitation.

Figure 11: Back scattered electron (BSE) image of a particle of 4-day Ash Grove Bypass Low, with a composition (see Table 8 ) of $\mathrm{CaCO}_{3}$. The accompanying calcium map shows a relatively uniform distribution of calcium throughout the particle.

Figure 12: Back scattered electron images of Ash Grove Bypass High: (a) virgin (noncarbonated) cement kiln dust, (b) 8-hour reacted cement kiln dust, and (c-d) 4-day reacted cement kiln dust. Figure 12 a show virgin candidates for these $\mathrm{Ca}(\mathrm{OH})_{2}$ centers. $\mathrm{CaCO}_{3}$ rings forming around $\mathrm{Ca}(\mathrm{OH})_{2}$ centers are evident in $4 \mathrm{~b}-\mathrm{d}$ with the rings growing in thickness over time 


\section{LIST OF TABLES}

$\underline{\text { TABLE }}$

$\underline{\text { PAGE }}$

Table 1: Composition (\% dry weight) of the cement kiln dust samples analyzed in this study based on x-ray fluorescence spectrometry, which yields mineral compositions in terms of oxide...

Table 2 Results of normative calculations of compositions for the three cement kiln dust types examined in this study. Data from x-ray fluorescence spectrometry data (Table 1), qualitative $x$-ray diffraction, and thermogravimetric analysis (Huntzinger et al. 2006a) were used in this calculation....

Table 3: Energy dispersive x-ray elemental microanalysis data (\% dry weight) for virgin (noncarbonated) Ash Grove Bypass High. Data corresponds to areas labeled on Figure 2 .

Table 4: Energy dispersive x-ray elemental microanalysis data (\% dry weight) corresponding to labeled areas on the Ash Grove Bypass High particle shown in Figure 7.

Table 5: Summary of the cement kiln dust (CKD) types with hypothesized precipitation mechanisms

Table 6: Energy dispersive x-ray elemental microanalysis data (\% dry weight) for locations marked on the Ash Grove Bypass High particles shown in Figure 8.

Table 7: Energy dispersive x-ray elemental microanalysis data (\% dry weight) for the Ash Grove Bypass High particles shown Figure 9.

Table 8: Energy dispersive x-ray elemental microanalysis data (\% dry weight) for the

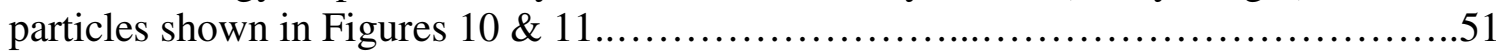

Table 9: Results from inductively coupled plasma mass spectrometry (ICP-MS) analysis.

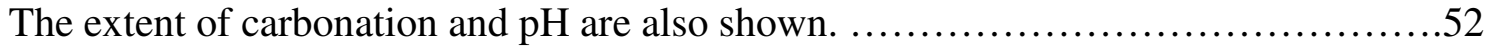

Table 10:Phase assemblage results from PHREEQC equilibrium analysis using x-ray fluorescence spectrometry with X-ray diffraction and thermal gravimetric analysis for starting cement kiln dust compositions. Three results are shown for each cement kiln dust type, using three $\mathrm{CO}_{2}$ concentrations, open and closed $0.035 \% \mathrm{CO}_{2}$ (atmospheric), and $80 \% \mathrm{CO}_{2}$ (concentration used in carbonation experiments) .................53 
Table 11: Elemental concentrations calculated by PHREEQC compared with the results from inductively coupled plasma optical emission spectrometry (ICP-OES) using ) using $\mathrm{x}$-ray fluorescence spectrometry with $\mathrm{x}$-ray diffraction and thermal gravimetric analysis for the starting composition. Three PHREEQC results are shown for each cement kiln dust type, using three $\mathrm{CO} 2$ concentrations: open and closed $0.035 \% \mathrm{CO} 2$ (atmospheric), and open $80 \% \mathrm{CO} 2$ (concentration used in carbonation experiments)...................54 


\section{LIST OF SUPPLEMENTARY FILES}

APPENDIX A: ESEM Stub Comparison ～～(Directory) (2.15 MB)

APPENDIX B: SEM-EDX Elemental Mapping ～(Directory) $\quad$ (34.7 MB)

APPENDIX C: SEM-EDX Microanalysis Data $\quad$ (Directory) (3.03 MB)

APPENDIX D: Additional SEM Images of CKD ～(Directory) (9.45 MB)

APPENDIX E: SEM Images of $\mathrm{CaO}$ and $\mathrm{Ca}(\mathrm{OH})_{2} \quad$ (Directory) (40.0 MB) 


\section{INTRODUCTION}

Carbon dioxide $\left(\mathrm{CO}_{2}\right)$ emissions are of primary concern due to the status of $\mathrm{CO}_{2}$ as a leading anthropogenic greenhouse gas (Falkowski et al. 2000). Annually over 25 billion tons of $\mathrm{CO}_{2}$ are released due to human activities (DOE-NETL 2006). Since the world's dependence on fossil fuels is difficult to lower, the capture or sequestration of $\mathrm{CO}_{2}$ is an important consideration to reduce the effects of emissions (Butt et al. 1999). A possible method to reduce anthropogenic $\mathrm{CO}_{2}$ emissions is $\mathrm{CO}_{2}$ sequestration as a mineral carbonate.

Mineral sequestration of $\mathrm{CO}_{2}$ involves the reaction of a mineral oxide with $\mathrm{CO}_{2}$ to form a mineral carbonate. Common oxides that will readily form stable mineral carbonates are magnesium oxide $(\mathrm{MgO})$ and calcium oxide $(\mathrm{CaO})$. Due to their vast availability, ultra mafic rocks rich in $\mathrm{MgO}$ (in silicate form) have been studied the most for potential geological sequestration (Lacker et al. 1997: Butt et al. 1999; Guthrie et al. 2001; Fauth et al. 2002; Wolf et al. 2004). For rapid carbonation, preprocessing is needed to extract the $\mathrm{MgO}$ out of the ore rock and transform it to the more reactive hydroxide phase as $\mathrm{Mg}(\mathrm{OH})_{2}$ (Butt et al. 1999).

Potential sources of readily available $\mathrm{CaO}$ are industrial oxide wastes. The carbonation of $\mathrm{CaO}$ and $\mathrm{Ca}(\mathrm{OH})_{2}$ progresses rapidly, with completion possible in minutes (Lacker et al 1997) making industrial oxide wastes logical candidates for geological sequestration. Bertos et al. (2004a) examined the carbonation of municipal solid waste incinerator (MSWI) ash in an aqueous solution at elevated temperatures and pressures. They utilized scanning electron microscopy (SEM), x-ray diffraction (XRD), and differential thermogravimetrical analysis (DTA) to characterize the changes occurring 
due to carbonation. The study examined bottom ash, which is mostly aluminosilicate phases with some metallic components, and air pollution control (APC) residues, which are a mixture of carbon and lime $(\mathrm{CaO})$ with heavy metals, soluble salts, and chlorinated compounds. In both ash segments, $\mathrm{CaCO}_{3}$ contents increased due to carbonation, more so in the APC due to the higher initial $\mathrm{CaO}$ content. Depleted calcium silicates were also found in proximity to newly precipitated $\mathrm{CaCO}_{3}$, suggesting calcium silicates had contributed $\mathrm{Ca}^{2+}$ for carbonation.

Huijgen et al. (2005) investigated the carbonation of steel slag using methods similar to Bertos et al. (2004a) such as scanning electron microscopy and energy dispersive x-ray (SEM-EDX) to investigate the reaction pathways. Huijgen et al. (2005) examined the use of steel slag for $\mathrm{CO}_{2}$ sequestration because of its high calcium silicate content. They used a water to solid ratio of 20:1 and reaction temperatures of up to $250^{\circ} \mathrm{C}$. After the rapid carbonation of all the $\mathrm{Ca}(\mathrm{OH})_{2}$ present in the steel slag, they proposed that $\mathrm{Ca}^{2+}$ was leached from calcium silicates to form $\mathrm{CaCO}_{3}$. Theses studies found that the carbonation of industrial mineral oxide wastes is a feasible approach for $\mathrm{CO}_{2}$ sequestration, however both used large ( $>1$ water to solid ratios) and elevated temperatures and pressures, which require energy.

In a study on the accelerated carbonation of cement-based materials for the stabilization of waste materials, Bertos et al. (2004b) observed that the diffusion of $\mathrm{CO}_{2}$ into a particle causes leaching and precipitation of $\mathrm{CaCO}_{3}$ in the intraparticle pores. This leaves a growing front of carbonated material and an inner zone of non-carbonated material. Tightly packed, fibrous calcite crystals were also observed in the carbonated products. Carbonation is a natural process in the manufacture of cement-based (concrete) 
materials but accelerated carbonation of wastes with cementitious materials might allow for increased stability during disposal.

Huntzinger et al. (2006a) studied the rate and extent of carbonation in cement kiln dust (CKD), a waste byproduct of cement manufacturing, using CKD samples from Ash Grove Cement Company. $\mathrm{CKD}$ is rich in $\mathrm{CaO}$, typically containing lime in amounts ranging from 20-60\% (dry weight basis). Huntzinger et al. (2006a) used composition information (fluorescence spectrometry $(\mathrm{XRF})$ and quantitative $\mathrm{x}$-ray diffraction (QXRD)) to estimate a theoretical capacity for $\mathrm{CO}_{2}$. Batch carbonation experiments provided measures of the actual extent of carbonation. Batch reactions were conducted in a reaction box with a relative humidity $>98 \%$ and $\mathrm{CO}_{2}$ concentration between 75 and $85 \%(\mathrm{v} / \mathrm{v})$. Characterization using QXRD utilizing the relative intensity ratio (RIR) method along with thermogravimetric analysis with differential thermal analysis (TGA/DTA) allowed quantification of changes in total carbonates due to carbonation. An overall increase of up to $20.7 \%$ in calcite content after carbonation was determined with QXRD. Independently, greater extents of carbonation (26-30\%) were measured with TGA/DTA, suggesting that calcite polymorphs or poorly formed calcite were also present.

Huntzinger et. al. (2006b) performed column experiments with CKD to study the rates and extent of the reactions under dynamic (i.e., flowing $\mathrm{CO}_{2}$ gas) conditions. Slower rates and hence, lesser extents of carbonation were measured in the columns compared to the static batch experiments, suggesting reaction mechanisms such as intraparticle diffusion could be affecting the carbonation. 
Lacking in the mechanistic studies by Huntzinger et al. (2006a, b) were microanalysis and characterization of the effect of carbonation on the CKD at the particle scale. This study investigates the reaction participants and pathways in the carbonation of CKD using SEM-EDX. In addition, environmental electron microscopy (ESEM) was used to compare particles before and after carbonation to document morphological changes. These investigations into the carbonation reaction of CKD could answer questions regarding the slowing of the reaction rates and the limitations on the extents of sequestration, leading to better utilization of the sequestration technology.

\subsection{Carbonation Chemistry}

The composition of CKD is extremely variable and depends on the kiln type, cement type, source of the raw materials, and fuels being used (van Oss \& Padovani 2003). Most CKD is partially calcined and contains up to $60 \%$ free lime $(\mathrm{CaO})$,

portlandite $\left(\mathrm{Ca}(\mathrm{OH})_{2}\right)$, and reactive cement species (i.e., calcium silicates) (Klemm 1994;

Corish \& Coleman 1995; van Oss \& Padovani 2003; Sreekrishnavilasam et al. 2006). Other mineral oxides such as $\mathrm{MgO}, \mathrm{Na}_{2} \mathrm{O}, \mathrm{Fe}_{2} \mathrm{O}_{3}$, and $\mathrm{K}_{2} \mathrm{O}$ can be present as complex compounds $\left(e . g\right.$., $\mathrm{NaCl}$ or $\left.(\mathrm{K}, \mathrm{Na})_{3} \mathrm{Na}(\mathrm{SO} 4)_{2}\right)$ in varying amounts but in a lesser total amount than $\mathrm{CaO}$. Volatile metals and alkali compounds (sulfates and chlorides) get concentrated in CKD (Klemm 1994; Corish \& Coleman 1995). Alkali limits for cement in some states prevents the recycling of CKD into the raw feed (limestone, clay, sandstone, iron ore, etc.) due to the alkali-silica reaction (ASR) that can occur in concrete. Non-recyclable CKD is either sold for other uses (agriculture, land stabilization, etc.) or land filled (van Oss \& Padovani 2003). 
Due to the heterogeneous nature of CKD, several carbonation reactions are possible. Sequestration reactions with mineral oxides follow a general form:

$$
\text { Mineral Oxide }+ \text { Water } \rightarrow \text { Mineral Hydroxide(s) }
$$

Mineral Hydroxide(s) + Carbon Dioxide $\rightarrow$ Mineral Carbonate(s)

Free $\mathrm{CaO}$ can be present in large amounts in $\mathrm{CKD}$, especially in alkali bypass dust with 27\% (dry weight) or more free $\mathrm{CaO}$ (Klemm 1994; Sreekrishnavilasam et al. 2006). Therefore, calcium carbonate is expected to be the main carbonation product. Unknown is in the form the calcium carbonate will occur as a result of carbonation: calcite crystals, calcite polymorphs, or amorphous precipitates.

Carbonation of $\mathrm{CaO}$ is a two-step reaction involving the intermediate formation of $\mathrm{Ca}(\mathrm{OH})_{2}$ (calcium hydroxide or portlandite). Both reactions occur readily at ambient temperatures and pressures (Steinour 1959; Bertos et al. 2004a; Huijgen et al. 2005).

$$
\begin{gathered}
\mathrm{CaO}+\mathrm{H}_{2} \mathrm{O} \rightarrow \mathrm{Ca}(\mathrm{OH})_{2} \\
\mathrm{Ca}(\mathrm{OH})_{2}+\mathrm{CO}_{2} \rightarrow \mathrm{CaCO}_{3}+\mathrm{H}_{2} \mathrm{O}
\end{gathered}
$$

Similar reactions can occur with other oxides (e.g., sodium, potassium, and magnesium); however, these reactions do not occur as readily at ambient temperatures and pressures (Steinour 1959; Bertos et al. 2004a).

$$
\begin{gathered}
\mathrm{Na}_{2} \mathrm{O}+\mathrm{H}_{2} \mathrm{O} \rightarrow \mathrm{Na}_{2}(\mathrm{OH})_{2} \\
\mathrm{Na}_{2}(\mathrm{OH})_{2}+2 \mathrm{CO}_{2} \rightarrow 2 \mathrm{NaHCO}_{3} \\
\mathrm{Na}_{2}(\mathrm{OH})_{2}+\mathrm{CO}_{2} \rightarrow \mathrm{Na}_{2} \mathrm{CO}_{3}+\mathrm{H}_{2} \mathrm{O} \\
\mathrm{K}_{2} \mathrm{O}+\mathrm{H}_{2} \mathrm{O} \rightarrow \mathrm{K}_{2}(\mathrm{OH})_{2}
\end{gathered}
$$




$$
\begin{gathered}
\mathrm{K}_{2}(\mathrm{OH})_{2}+2 \mathrm{CO}_{2} \rightarrow 2 \mathrm{KHCO}_{3} \\
\mathrm{~K}_{2}(\mathrm{OH})_{2}+\mathrm{CO}_{2} \rightarrow \mathrm{K}_{2} \mathrm{CO}_{3}+\mathrm{H}_{2} \mathrm{O} \\
\mathrm{MgO}+\mathrm{H}_{2} \mathrm{O} \rightarrow \mathrm{Mg}(\mathrm{OH})_{2} \\
\mathrm{Mg}(\mathrm{OH})_{2}+\mathrm{CO}_{2} \rightarrow \mathrm{MgCO}_{3}+\mathrm{H}_{2} \mathrm{O}
\end{gathered}
$$

The weathering of calcium silicates present in CKD may also release $\mathrm{Ca}^{2+}$ for carbonation. However, this is a slower reaction than the carbonation of $\mathrm{CaO}$. The reaction path is summarized below (Huntzinger et al. 2006a):

$$
\begin{gathered}
\mathrm{CaSiO}_{3}+2 \mathrm{H}_{2} \mathrm{O}+2 \mathrm{CO}_{2} \rightarrow \mathrm{Ca}^{2+}+2 \mathrm{HCO}_{3}{ }^{-}+2 \mathrm{H}^{+}+\mathrm{SiO}_{3}{ }^{2+} \rightarrow \\
\mathrm{CaCO}_{3}+\mathrm{SiO}_{2} \cdot \mathrm{H}_{2} \mathrm{O}+\mathrm{H}_{2} \mathrm{O}+\mathrm{CO}_{2}
\end{gathered}
$$

\subsection{Ancillary Effects of Carbonation}

In addition to lowering $\mathrm{CO}_{2}$ emissions, the use of industrial wastes for $\mathrm{CO}_{2}$ sequestration may have positive effects on the composition of the waste by lowering the caustic nature and/or the mobility of heavy metals present in the waste. Several studies investigated the effects of carbonation on the leaching of heavy metals from industrial wastes such as MSWI ash (Meima et al. 2002; Ecke 2003; Bertos et al. 2004a; Van Gerven et al. 2005) and steel slag (Huijgen \& Comans 2006). Five mechanisms have been hypothesized that would explain changes in leaching caused by carbonation: (1) precipitation of carbonates, (2) pH-neutralization, (3) formation of minerals other than carbonates, (4) coprecipitations, and (5) sorption of metals on fresh precipitation surfaces (loc. cit. Huijgen \& Comans (2006)). In the carbonation of CKD, all of these mechanisms are possible. Although discerning the different mechanisms responsible for lessening the 
leaching potential of CKD is outside the scope of this study, preliminary laboratory experiments were performed to examine the changes in trace metal solubility caused by carbonation.

Thermodynamically based geochemical modeling can provide insight into the expected reactants and products of the carbonation reactions. PHREEQC, a geochemical modeling program developed by the United States Geological Survey (USGS 1998), uses the equilibrium chemistry of aqueous solutions containing minerals and gases to determine reaction products for many sorts of geochemical reactions. Halim et al. (2005) investigated the use of PHREEQC for the leaching of metals from cement to investigate the use of cement for metals stabilization. Their study used kinetic simulations, which gave similar results as their laboratory experiments. Because of industry design specifications, the composition of cement is better constrained than CKD and in Halim et al. (2005) a known amount of the heavy metal compounds was added, so the mixture compositions were well defined in their study. The use of a kinetic simulation would have been impractical for this present study due to a lack of detailed CKD composition. However, Halim et al. (2005) showed that the use of PHREEQC for studies on cementitious material is possible and can correlate well to laboratory studies. In this study, PHREEQC is used to determine the thermodynamically favorable products of the carbonation of the CKD types examined. It also provided information on the changes in Ca solubility caused by pH differences.

\section{OBJECTIVES AND SCOPE}

The primary objective of this study is to determine the nature of the carbonation reactions that occur in a mineralogically heterogeneous $\mathrm{CKD}$ at ambient temperatures 
and pressures. This will involve the determination of the active constituents of CKD and examination of the mechanisms of the predominate reactions. Additionally, the changes in trace metal solubility caused by carbonation are examined due to theories about reduction in metal solubility because of carbonation.

The scope of this work is limited to three CKD samples provided by Ash Grove Cement Company (Overland Park, Kansas). The three samples provide a spectrum of diverse CKD composition and include the two most prevalent production processes (dry and wet kilns). The carbonation of the samples was performed using near-pure ( $~ 80 \%$ v/v) $\mathrm{CO}_{2}$ at ambient temperature and pressure. Relative humidity was controlled to be near saturated (>98\%). The high-purity atmosphere is not representative of the complexity of flue gas mixtures but an important simplifying step in understanding the sequestration reactions that take place.

\section{EXPERIMENTAL MEthods}

The determination of the reactive components of CKD requires techniques with the ability to examine the chemical composition and mineralogical form. Scanning electron microscopy with energy dispersive x-ray spectroscopy (SEM-EDX) can characterize the spatial distribution of elements within and around CKD particles, but sample preparations for SEM preclude being able to visualize particular particles before and after carbonation to see the changes. Environmental scanning electron microscopy (ESEM) allows for direct particle comparison to determine morphological changes occurring due to the carbonation. In addition, analysis such as qualitative x-ray diffraction (QXRD) and thermal gravimetric analysis/differential thermal analysis (TGA/DTA) (Huntzinger et al. 2006a) allow for quantification of carbonates formed. The 
combination of these methods yields the different minerals being depleted and reacting with the carbon dioxide to form new carbonates.

Geochemical modeling is used to examine equilibrium reactions among CKD, water, and $\mathrm{CO}_{2}$ and to confirm the reactive constituents in the CKD. Analysis using inductively coupled plasma mass spectrometry examined the changes in metals solubility caused by carbonation.

\subsection{CKD Samples}

Ash Grove (AG) Cement Company (Overland Park, KS) provided freshly produced CKD samples from two cement manufacturing facilities. The oxide compositions obtained from x-ray fluorescence spectrometry (XRF) are provided in Table 1. Table 2 lists estimates of simplified compositions of major constituents calculated using normative calculations. Two of the samples are alkali by-pass dust from the production of different cement types, from Chanute, Kansas, using a modern, dry process facility with a precalcination unit. The composition of AG Bypass High is more typical of CKD produced at the Chanute plant than the composition of AG Bypass Low. AG Bypass High has a large lime content (37\% dry weight) and it represents a modern

production type, so it is of most interest to the $\mathrm{CO}_{2}$ sequestration investigation. The third sample is from the wet process facility in Midlothian, Texas (AG Wet).

\subsection{ESEM}

An environmental scanning electron microscope (Philips x140 ESEM (FEI Company, Hillsboro, Oregon)) was used for direct particle comparison. A virgin (noncarbonated) sample of each CKD type was mounted to an ESEM sample stub with a 
carbon adhesive tab and dispersed on the mount using pressurized air. The use of pressurized air to mount the samples allows for a more representative sample and spaces the particles for better viewing. The mounted virgin samples were examined with the ESEM at 15-20 kv and 2 - 3 torr, both of which were adjusted within this range to obtain clearest images. Specific particles were identified with the aid of a line grid etched into the carbon adhesive tab and imaged. After examining the virgin $\mathrm{CKD}$, the stubs were placed in a reaction box for an average of 36 hours. The reaction box is pictured in Figure 1. The box provided an environment where humidity and $\mathrm{CO}_{2}$ concentration could be controlled and monitored (see Huntzinger et al. (2006a) for more details). The stubs were re-examined in the ESEM and the particles compared with the respective pre-carbonation photographs to compare changes in the overall structure of the particles.

\subsection{SEM-EDX}

Virgin samples and samples that had been carbonated were examined by SEMEDX, using a PHILIPS XL40 Environmental Scanning Electron Microscope (FEI Company, Hillsboro, Oregon) equipped with an EDAX EDS detector (Mahwah, New Jersey) and a TexSEM Laboratories (Draper, Utah) Electron Back-Scatter Pattern Detector). Sample preparation involved impregnation with resin using an IU30 Vacuum Impregnation Unit (Logictech, Westlake, Ohio), mounting on glass slides, diamond polishing to obtain cross sections of the particles, washing with alcohol, and coating with 200-300A of carbon. Elemental mapping and EDX microanalysis of particles were conducted using a focused electron beam with an accelerating voltage of $15 \mathrm{KeV}$ and a working distance of $10 \mathrm{~mm}$. Each microanalysis was collected for 100 seconds of live time and was performed on 12 areas of each particle to acquire a representative average. 
Willemite $\left(\mathrm{Zn}_{2} \mathrm{SiO}_{4}\right)$ was used as an internal standard and was run between each analysis to obtain a beam correction factor. Calibration of the EDX was performed hourly (Peterson, personal communications, 2006).

Sodium (Na), magnesium (Mg), aluminum $(\mathrm{Al})$, silicon $(\mathrm{Si})$, phosphorus $(\mathrm{P})$, sulfur $(\mathrm{S})$, chloride $(\mathrm{Cl})$, potassium $(\mathrm{K})$, calcium $(\mathrm{Ca})$, manganese $(\mathrm{Mn})$, and iron $(\mathrm{Fe})$ were the major elements examined. SEM Quant (EDAX) automatically analyzed the collected EDX spectra using the $\mathrm{ZAF}(\mathrm{Z}=$ atomic number factor, $\mathrm{A}=$ absorption factor, $\mathrm{F}=$ characteristic fluorescence correction) correction method with a manual background correction performed. Due to the uncertainty determining weight percentages of elements with atomic numbers less than 11 , the data were not normalized to $100 \%$, which allowed combined oxygen $(\mathrm{O})$, hydrogen $(\mathrm{H})$, and carbon $(\mathrm{C})$ percentages to be determined from the difference. However, the presence of a $\mathrm{C}$ or $\mathrm{O}$ peak was noted during spectra collections to assist in identification of minerals.

\subsection{Thermodynamic Equilibrium Evaluations}

Batch equilibrium leaching experiments provides insight into the changes in metal leaching from CKD resulting from carbonation. Batch experiments were used to determine metal and mineral solution concentrations before and after carbonation. Additionally geochemical equilibrium modeling allows for examination of the theoretical results of carbonation to confirm that the observed reactions are thermodynamically favorable. 


\subsubsection{Laboratory Analyses}

Virgin and carbonated CKD were mixed in de-ionized water at a liquid to solid ratio of 10:1 for 48 hours using a stir bar, stir base, and allowing the mixture to be open to the atmosphere. The resulting solution was filtered through a 1- $\mu \mathrm{m}$ filter (Gelman Glass Acrodisc). University of Wisconsin Soils Laboratory (Verona, Wisconsin) conducted analysis of the solution samples using inductively coupled plasma mass spectrometry (ICP-MS) and inductively coupled plasma optical emission spectrometry (ICP-OES). The ICP-MS (VG PlasmaQuad PQ2 Turbo Plus ICP-MS (Thermo Elemental, Waltham, Massachusetts)) analysis examined chromium, copper, arsenic, cadmium, and lead concentration (UWM 2005a), while ICP-OES (Jarrell Ash IRIS High Resolution ICP-OES, (Genesis Laboratory Systems, Grand Junction, Colorado)) examined phosphorus, potassium, calcium, magnesium, sulfur, boron, magnesium, iron, copper, aluminum, and sodium concentration (UWM 2005b). The solution pH was also determined at this lab using a pH meter (Beckman Cat. No. 123144) with combination reference-glass electrode (Orion, Ross Sure-Flow combination, epoxy body Model \#8165) (UWM 2004). The results were obtained for comparison to the geochemical modeling describe below and to determine any changes in solubility of heavy metals and other minerals.

\subsubsection{Geochemical Equilibrium Modeling}

PHREEQC, which stands for $\mathrm{pH}$, redox, equilibrium, written in $\mathrm{C}$ programming language, is a modeling software from the USGS that performs low-temperature aqueous geochemical calculations (PHREECi, which is a version of PHREEQC with a user interface, was utilized in this study) (USGS 1998). The geochemical modeling uses 
thermodynamic principles to evaluate the reactions occurring between the compounds in the virgin CKD and water. Using a 10:1 liquid to solid ratio, each CKD type was reacted to equilibrium by PHREEQC with the use of the Lawrence Livermore National Library (LLNL) database. For these calculations, a simplified composition of each virgin CKD type was calculated (see Table 2). The normative calculation used the XRF oxide percentages and the following assumptions: (1) anhydrite was assumed as the only sulfate species; (2) calcite percentage was determined by QXRD analysis using the RIR method; and (3) portlandite percentages were taken from TGA/DTA analysis (Huntzinger et al. 2006a). Remaining $\mathrm{CaO}$ was assumed available for reaction and was lumped together as $\mathrm{CaO}$. Any Na present was assumed to be in halite and the remaining chloride was assumed to be in sylvite (when present as determined by QXRD) (Halim et al. 2005). Also, three atmospheres differing in $\mathrm{CO}_{2}$ composition were compared: closed system with atmospheric $(0.035 \% \mathrm{v} / \mathrm{v}) \mathrm{CO}_{2}$, open system with $0.035 \% \mathrm{CO}_{2}$, and open system with $80 \% \mathrm{CO}_{2}$ (similar to the reaction box conditions).

\section{Results AND Discussion}

The focus of this study was to determine the nature of the carbonation reactions that occur in a mineralogically heterogeneous CKD at ambient temperatures and pressures. ESEM was selected to allow for comparison of specific CKD particles in their virgin and carbonated states, making it possible to determine changes in morphology occurring due to carbonation. SEM-EDX analysis provides information on the distribution of elements and allows for elemental microanalysis of particles to determine changes caused by and products of the carbonation. It can also offer insight into the mechanisms of the reactions. Combined with QXRD and TGA/DTA (Huntzinger et al. 
2006a), which also provide information on changes in carbonates and crystalline compounds, conclusions can be drawn regarding the carbonation products and reactions.

Three CKD samples with diverse virgin compositions (Tables $1 \& 2$ ) were examined. The high $\mathrm{CaO}$ composition of the AG Bypass High and its modern production type (dry kiln) makes it the better candidate for $\mathrm{CO}_{2}$ sequestration. It is therefore the focus of the majority of the discussions below.

\subsection{Characteristics of Virgin CKD}

Virgin (noncarbonated) samples of each CKD type were analyzed to enable comparison with the carbonated CKD. Figure 2 identifies locations selected due to presence of elements of interest (obtained from elemental maps), where the results of EDX microanalysis performed on virgin AG Bypass High are provided in Table 3. The expected major constituents were: portlandite, calcite, and lime, along with quartz, anhydrite, iron, aluminates, calcium silicates, and alkali compounds. Of the five analyzed areas, three (see Table 3: A, B, and E) were silicate compounds with calcium, potassium, and iron. Areas A and B appear to be a fused particle both with different silicate compositions. Area A has calcium silicate composition with some aluminum (Al) and iron $(\mathrm{Fe})$, and Area B is possibly potassium $(\mathrm{K})$ silicate with $\mathrm{Al}$ and $\mathrm{Ca}$. Also identified in the microanalysis was a particle of quartz (C), with a thin calcium silicate rim (E) on the outside. Similar quartz particles with calcium silicate rims were found in the other CKD types as well (Appendix C). Particle $\mathrm{C}$ in Figure 2 has a $\mathrm{Ca}$ composition consistent with $\mathrm{Ca}(\mathrm{OH})_{2}$. The Ca content ranged from 45 to $54 \%$ with varying small amounts of sulfur (S). This suggests some $\mathrm{S}$ compounds, possibly anhydrite, were also present in the particle. Although a few calcium silicate compounds were found with SEM-EDX, there 
were none detected by QXRD analysis in all samples, suggesting they are a minor constituent $(<2 \%)$ of these CKD samples.

\subsection{Reaction Participants and Products}

Results from TGA/DTA analyses for all CKD types showed an increase in carbonates. QXRD analysis also confirmed an increase (13-20\% depending on CKD type) in crystalline calcite. TGA/DTA showed slightly higher increases (14-30\% depending on CKD type) compared to QXRD because it measures amorphous (unstructured) calcium carbonate and trace amounts of other mineral carbonates (Huntzinger et al. 2006a).

Direct particle comparisons conducted using ESEM showed precipitation of carbonates on the outside of particles (Figure 3). This precipitation was observed in all particles directly examined by ESEM for the sample of AG Bypass High and the majority of AG Bypass Low and AG Wet particles (Appendix A). Similar precipitation on the outside of particles was observed in preliminary SEM investigations on carbonated $\mathrm{CaO}$ and $\mathrm{Ca}(\mathrm{OH})_{2}($ Appendix $\mathrm{E})$. An indication of carbonate precipitation is the increased clarity between the virgin and carbonated images. This is due to the higher density of carbonates compared to oxides, allowing better electron imaging in ESEM. In addition to carbonate precipitation, AG Bypass Low (Figure 4) displayed precipitation of sylvite $(\mathrm{KCl})$ crystals, which initially dissolved due to its high solubility and then reprecipitated as the sample dried. The AG Wet (Figure 5) shows larger calcite crystal growth along with a likely amorphous carbonate precipitate. Fibrous crystals are characteristic of calcite, which has several crystal habits (Taylor 1997). Bertos et al. (2004b) found similar calcite crystals in their examination of accelerated carbonation of cement. 
Further support for the precipitation of $\mathrm{CaCO}_{3}$ is shown in EDX elemental maps of $\mathrm{Ca}$ in virgin (Figures 6a-b), 8-hr reacted (Figures 6c-d) and 4-d reacted High Bypass CKD (Figures 6e-f). The back scattered electron (BSE) images on the right show the area mapped, and the Ca maps on the left show the changes in the distribution. The distribution of calcium appears to grow $(\sim 30 \%)$ over time as the higher Ca content particles release $\mathrm{Ca}^{2+}$, which carbonates and precipitates. Elemental maps of AG Wet and AG Bypass Low show the same Ca distribution growth (Appendix B).

EDX microanalysis of each carbonated CKD type showed the presence of $\mathrm{CaCO}_{3}$ both as separate particles and as precipitates on Ca-containing particles. AG High Bypass CKD had many (majority of reacted) particles with a center composition similar to $\mathrm{Ca}(\mathrm{OH})_{2}$ and a outer ring of $\mathrm{CaCO}_{3}$. In the Ca maps, these are the particles with Ca-rich centers and lower Ca content outer rings (see Figure 6f). The nature of the precipitation will be discussed further below.

\subsection{Reaction Pathways}

In $\mathrm{CKD}$ at ambient temperatures and pressures, the carbonation of $\mathrm{Ca}$ is possible either by the release of $\mathrm{Ca}^{2+}$ due to silicate weathering or from the carbonation of $\mathrm{Ca}^{2+}$ present in $\mathrm{CaO}$ or $\mathrm{Ca}(\mathrm{OH})_{2}$. Evidence of the first pathway is the presence of calcium silicates with lower Ca percentages than silicates in the virgin samples. The particle in Figure 7 illustrates results with a depleted Ca-silicate center and $\mathrm{CaCO}_{3}$ precipitated adjacent, apparently connected, to the particle (Huijgen et al. 2005; Bertos et al. 2004) Also shown in Figure 7 are the accompanying $\mathrm{Ca}$ and silicon (Si) elemental maps illustrating $\mathrm{Si}$ and $\mathrm{Ca}$ in the center with only $\mathrm{Ca}$ present on the edge of the particle. 
Table 4 shows the results of the EDX analysis on this particle and the results indicate that potassium $(\mathrm{K})$ substitution may have been possible in the carbonate and silicate sections of the particle. Traces of sodium $(\mathrm{Na})$ and iron $(\mathrm{Fe})$ are also present in the carbonate material. The $\mathrm{Ca}$ content ( $34.8 \mathrm{wt} \%)$ of the edge is not as high as it would be for pure $\mathrm{CaCO}_{3}$ (40\% dry weight Ca) but some substitution and intermixed silicate material is probable. Due to the slow rate that silicates weather, it is also possible that the depleted calcium silicate species present in this study would have continued, with increased time (months to years), to contribute $\mathrm{Ca}^{2+}$ for the formation of $\mathrm{CaCO}_{3}$.

The carbonation of $\mathrm{CaO}$ and $\mathrm{Ca}(\mathrm{OH})_{2}$ was dominant due to the high $\mathrm{CaO}$ and $\mathrm{Ca}(\mathrm{OH})_{2}$ contents of the CKD samples, the slower reaction rate of calcium silicates (can be years compared to minutes for $\left.\mathrm{CaO} / \mathrm{Ca}(\mathrm{OH})_{2}\right)$ at theses temperatures and pressures, and their trace presence $(<2 \%)$ in these CKD samples. QXRD analysis on virgin and carbonated samples of all three $\mathrm{CKD}$ types found that $\mathrm{CaO}$ was not present in the carbonated product. This is probably due to the immediate transformation of $\mathrm{CaO}$ to $\mathrm{Ca}(\mathrm{OH})_{2}$ in the presence of water. $\mathrm{Ca}(\mathrm{OH})_{2}$ was not detected in the AG Bypass Low but was found in the 4-d carbonated samples of AG Bypass High and AG Wet, which suggests that full carbonation of $\mathrm{Ca}(\mathrm{OH})_{2}$ was not reached in those CKD samples (Huntzinger et al. 2006a).

\subsection{Precipitation Mechanisms}

For the carbonation of $\mathrm{CaO}$ and $\mathrm{Ca}(\mathrm{OH})_{2}$, the SEM-EDX microanalysis investigations found three possible mechanisms for the precipitation of $\mathrm{CaCO}_{3}$ and that each CKD type showed unique combinations of the three mechanisms. The three mechanisms are: (1) diffusion of $\mathrm{CO}_{2}$ into a $\mathrm{CaO}$ or $\mathrm{Ca}(\mathrm{OH})_{2}$ particle with precipitation 
on the outside of the particle and the intraparticle pores causing the formation of a carbonate ring that grows inward with time, (2) precipitation of $\mathrm{CaCO}_{3}$ through nucleation on existing calcite particles, and (3) the precipitation of $\mathrm{CaCO}_{3}$ out of saturated aqueous solution. Table 5 summarizes the precipitation mechanisms based on CKD types. Further explanations of each mechanism are provided below.

The diffusion of $\mathrm{CO}_{2}$ into particles of $\mathrm{CaO}$ or $\mathrm{Ca}(\mathrm{OH})_{2}$ was the main $\mathrm{CaCO}_{3}$ precipitation mechanism in the AG Bypass High. Figure 8 displays particles from the 4-d reacted High Bypass CKD, and Table 6 lists corresponding EDX elemental results. The particle in Figure $8 \mathrm{~b}$ corresponds to the highlighted particle in the Ca map in Figure $6 f$. This particle shows a center with higher $\mathrm{Ca}$ content and $\mathrm{CaCO}_{3}$ edge. In a study on the accelerated carbonation of cement materials, Bertos et al. (2004b) discusses the diffusion of $\mathrm{CO}_{2}$ into a particle which causes leaching and precipitation of $\mathrm{CaCO}_{3}$ in the particle pores. This follows the scenario of the hydration of $\mathrm{CaO}$ (or the presence of $\mathrm{Ca}(\mathrm{OH})_{2}$ ) and the diffusion of $\mathrm{CO}_{3}{ }^{2-}$ (aq) into the particle. In Figure 8, the average center compositions, while close to that of $\mathrm{Ca}(\mathrm{OH})_{2}$ at $\sim 50 \mathrm{wt} \% \mathrm{Ca}$, had variable Ca percentages over the 12 recorded analyses for each from $40 \%\left(\mathrm{CaCO}_{3}\right)$ to $54 \%\left(\mathrm{Ca}(\mathrm{OH})_{2}\right)$. This suggests a mixed $\mathrm{CaCO}_{3} / \mathrm{Ca}(\mathrm{OH})_{2}$ composition in the centers of these particles, which is likely caused by precipitation of $\mathrm{CaCO}_{3}$ in the intraparticle pores.

The formation of an outer ring of $\mathrm{CaCO}_{3}$ is due to interaction of the $\mathrm{CO}_{3}{ }^{2-}$ (aq) with the $\mathrm{Ca}^{2+}{ }_{(\mathrm{aq})}$ and the water on the outside of the particle. As the ring grows inward, it may slow further diffusion of $\mathrm{CO}_{3}{ }^{2-}$ (aq) into the micro-pore system. An interesting difference in the two particles illustrated in Figure 8 includes the thickness of this carbonate ring. The Ca content of the ring in Figure 8b compared to the thinner carbonate ring in Figure 8a 
indicates that the average $\mathrm{Ca}$ content of this ring is $40.5 \mathrm{wt} \%$. This is higher than the average of $36 \mathrm{wt} \%$ shown in Figure 8a. The greater porosity of the thinner ring in Figure 8a could cause this difference in Ca content.

Figure 9 illustrates two particles of $\mathrm{CaCO}_{3}$ found in the samples of $\mathrm{AG}$ Bypass High. Table 7 summaries the EDX results for these particles. In this case, time appears not to be a factor as the 8-hr carbonated particle is similar both mineralogically and morphologically to the 4-d carbonated particle, suggesting a relatively fast carbonation reaction has occurred. Both particles have the same average Ca content of $37 \%$ (dry weight). Their morphologies are similar to the carbonate ring in Figure $8 \mathrm{~b}$. This could indicate that these particles (Figure 9) were originally smaller particles with compositions like the centers of Figures 8a-b and completely carbonated. A second possibility is that these particles were originally smaller and entirely $\mathrm{CaCO}_{3}$ and acted as a nucleus for additional calcite precipitation. The appearance of different morphological regions in the particles suggest either possibility is plausible.

AG Wet experienced similar carbonation mechanisms to the AG Bypass High. Figure 10 illustrates a 4-d carbonated particle of the AG Wet CKD. The elemental analysis (Table 8) of this particle shows a composition of $\mathrm{CaCO}_{3}$. The particle has a small standard deviation of $1.0 \%$ in regards to $\mathrm{Ca}$ content, which suggests constant $\mathrm{CaCO}_{3}$. Examination of the morphology of this particle reveals an altered edge around the particle. Although this edge is also $\mathrm{CaCO}_{3}$, its morphology is more porous. This may indicate that this edge is precipitated $\mathrm{CaCO}_{3}$ through nucleation onto the existing $\mathrm{CaCO}_{3}$ center of the particle. The Ca map for this particle confirms that the Ca content is relatively constant through the particle. Other particles similar to this one were observed 
in this sample. This precipitation mechanism is also shown in Figure 5 with the direct particle comparison result for AG Wet. The expected cross section of the carbonated particle in Figure 5 would be close to identical to the particle seen in Figure 10.

The AG Bypass Low CKD does not have a typical composition for CKD, containing sylvite $(\mathrm{KCl})$ at $38 \%$ (dry weight) or greater (Table 2). During carbonation, samples of AG Bypass Low absorbed water vapor to the point where liquid water formed and practically submerged the samples. Separate water-vapor-absorption experiments with pure $\mathrm{KCl}$ confirmed that the water was forming from dissolution of sylvite and condensation. Figure 11 shows a 4-d carbonated AG Bypass Low particle that has a more porous morphology than the AG Wet particle (Figure 10) and AG Bypass High particles (Figure 11). This particle appeared characteristic of $\mathrm{CaCO}_{3}$ in the 4-d AG Bypass Low sample. A possible explanation is a larger presence of water during carbonation. The increased water dissolved all $\mathrm{CaO}$ and $\mathrm{Ca}(\mathrm{OH})_{2}$, both of which subsequently carbonated and precipitated $\mathrm{CaCO}_{3}$ as it dried, which might explain the porous morphology. A similar mechanism occurred with the sylvite present in the sample. Nucleation may also be a contributing factor to the precipitation mechanism and a combination of both mechanisms is probable in this case.

\subsection{Effects of Reaction Rates}

Overall, the amount of carbonation in samples grew with longer carbon dioxide exposure times. However, more than 50\% of the carbonation extent was reached within 2 days with a slowing of the carbonation after that (Huntzinger et al. 2006a). Although not focused on rate, this study conducted a preliminary look at differences in mineralogical changes over time. Only the AG Bypass High was examined at two time intervals (8-hr 
and 4-d) with only slight differences found related to the carbonate ring formation. The progression of carbonation with time was apparent in the thickness of the carbonation rings. Figure 12 shows images of virgin (Figure 12a), 8-hr reacted (Figure 12b) and 4-d reacted (Figures 12c-d) AG Bypass High. Identified in similar particles in the virgin AG Bypass High was $\mathrm{Ca}(\mathrm{OH})_{2}$. The carbonated ring present on the 8-hr particle shown in Figure $12 \mathrm{~b}$ is only one-fourth the size: $\sim 1 \mu \mathrm{m}$ compared to the $4-\mathrm{d}$, which had a $\sim 4 \mu \mathrm{m}$ carbonate ring. The thinner 8-hr ring also appears more porous than the thicker 4-d ring, suggesting a slower reaction rate in the 4-d ring, maybe due to slower vapor/aqueous diffusion as carbonation proceeded. Figure 12c shows a group of these particles from the 4-d sample all with similar thicknesses of carbonate rings.

Cross-sectional area characterization of these particles from SEM images allowed for independent estimation of the overall sequestration extent. By comparing the volume of the particles to the volume of the carbonate rings, assuming the particles are spheres, a percent carbonated was determined for 20 representative particles in the 4 - $\mathrm{d}$ carbonated AG Bypass High. An average of $75 \%$ carbonation, with a standard deviation of $12 \%$, was determined. This correlates well with the $83 \%$ extent of carbonation observed by Huntzinger et al. (2006a) for this CKD type after 4-d of carbonation in batch tests.

\subsection{Thermodynamic Equilibrium Results}

In addition to sequestering $\mathrm{CO}_{2}$, the carbonation of $\mathrm{CKD}$ may lower the mobility of trace heavy metals present in the dust. This could lower the hazardous nature of CKD and allow for easier disposal or for reuse in agriculture or construction. A preliminary evaluation of changes due to carbonation in trace metals solubility in the CKD was performed by mixing virgin and carbonated CKD with DI water and analyzing the 
solution with ICP-MS. Geochemical modeling was used to confirm reactive CKD species and to investigate changes in mineral solubility. These were not primary objectives of this study but do provide a preliminary groundwork for further investigation regarding change in metals mobility caused by carbonation.

\subsubsection{Laboratory Analysis}

Table 9 displays the results of ICP-MS analysis performed on the solution samples. A decrease in solubility of chromium $(\mathrm{Cr})$ and lead $(\mathrm{Pb})$ due to carbonation is evident in all of the CKD types. The solubility of copper $(\mathrm{Cu})$ also decreased considerably in the AG Bypass Low and AG Wet due to carbonation. Van Gerven et al. (2005) observed that carbonate formation was responsible for a decrease in $\mathrm{Cr}$ and $\mathrm{Cu}$ leaching from MSWI-bottom ash. The results of this study correspond well with the observation of an increase in carbonates. A decrease in $\mathrm{pH}$ did not contribute to the reduction in metals leaching as the change in $\mathrm{pH}$ (see Table 9) in these cases is minimal, and neutral levels were not reached at this extent of carbonation (4 d). Another possible explanation (at least in the AG Bypass Low) is the substitution of heavy metals into the sylvite $(\mathrm{KCl})$ structure during carbonation due to the dissolution of $\mathrm{KCl}$. This would also explain the shift in the $\mathrm{KCl}$ peak noticed in QXRD spectra of this CKD sample (Huntzinger et al. 2006a). These preliminary results should encourage TCLP (toxicity characteristic leaching procedure) testing of virgin and carbonate CKD samples for further information regarding leaching behavior. 


\subsubsection{Geochemical Equilibrium Modeling}

PHREEQC modeling predicted that the $\mathrm{CaO}$ and $\mathrm{Ca}(\mathrm{OH})_{2}$ present in $\mathrm{CKD}$ react completely to form $\mathrm{CaCO}_{3}$ in the presence of atmospheric $\mathrm{CO}_{2}(0.035 \%)$. The PHREEQC estimated solution composition varied widely depending on the level of $\mathrm{CO}_{2}$ present and the starting mineralogical composition. The starting composition was calculated using QXRD, TGA/DTA, and XRF data (Huntzinger et al. 2006a) along with stoichiometry. This simplified composition estimate is listed in Table 2. The modeling was conducted in three different $\mathrm{CO}_{2}$ environments, one where atmospheric $\mathrm{CO}_{2}$ $(0.035 \%)$ was present with no replenishment (closed), one with atmospheric levels of $\mathrm{CO}_{2}$ and infinite replenishment (open), and open with $80 \% \mathrm{CO}_{2}$. The absence of $\mathrm{CO}_{2}$ was tested to simulate a system closed to $\mathrm{CO}_{2}$. The concentration of $\mathrm{CO}_{2}$ did not affect the complete conversion of lime $(\mathrm{CaO})$ into portlandite $\left(\mathrm{Ca}(\mathrm{OH})_{2}\right)$, this occurred in the $0 \%$ $\mathrm{CO}_{2}$ atmosphere as well (Table 10). In scenarios with $\mathrm{CO}_{2}$, all portlandite was converted to calcite $\left(\mathrm{CaCO}_{3}\right)$ regardless of $\mathrm{CO}_{2}$ concentration if it was above zero. The laboratory and carbonation reactions were constrained by time and neither reached full equilibrium with $\mathrm{CO}_{2}$. However the PHREEQC simulations represent results that have reached full equilibrium with $\mathrm{CO}_{2}$.

Comparison of the PHREEQC mineral concentration results with those from ICPOES is listed in Table 11. $\mathrm{pH}$ values for the three $\mathrm{CO}_{2}$ concentrations show that the $\mathrm{pH}$ closest to the value obtained from the laboratory analysis is that of the closed $(0 \%) \mathrm{CO}_{2}$ system. This indicates that equilibrium with $\mathrm{CO}_{2}$ was probably not reached in the laboratory experiments. When $\mathrm{CO}_{2}$ is added to the system $(1 \mathrm{~mol}$ in this case which acted as an infinite supply compared to the amount of $\mathrm{CKD}$ ), the $\mathrm{pH}$ drops to a neutral range 
(Table 11). The $\mathrm{pH}$ affects the solubility of $\mathrm{Ca}$ with the solubility being higher at $\mathrm{pH}$ of 12 and 12.5 than at neutral $\mathrm{pH}$ of 7.5-8.0. Below a $\mathrm{pH}$ of 6.0 the solubility of $\mathrm{Ca}$ again rises. Other minerals such as $\mathrm{K}, \mathrm{Na}$, and $\mathrm{S}$ are not affected as significantly by $\mathrm{pH}$.

One contributor to the differences in mineral concentration between PHREEQC and ICP-OES analyses is the uncertainty in the compositions for the CKD. The estimation does not work for every mineral measured within a CKD type in the $0 \% \mathrm{CO}_{2}$ simulation. Although the exact composition is not correct for the PHREEQC analyses, the conclusions regarding complete depletion of $\mathrm{CaO}$ and $\mathrm{Ca}(\mathrm{OH})_{2}$ correspond well with data obtained from SEM-EDX, QXRD, and TGA/DTA.

\section{CONCLusions}

An examination of the effects of carbonation on CKD, a waste by-product of cement manufacturing, was conducted in order to characterize the main carbonation reactions. The mineralogical and morphological changes occurring in the CKD during carbonation were ascertained through a combination of microscopic and characterization methods. CKD particles before and after carbonation were examined using ESEM for morphological changes and elemental microanalysis of carbonated particles and cross sections of particles using SEM-EDX to determine dominant reactions and their pathways. Additional analyses from XRD and TGA/DTA from Huntzinger et al. (2006a) complemented this work.

The three CKD types examined vary greatly in composition. The AG Bypass High contains $36 \%$ available $\mathrm{CaO}$, AG Wet contains $22 \%$, while AG Bypass Low contains $11 \%$. These amounts factor into the carbonation potential of the CKD. The amount of sylvite differs as well, with AG Bypass Low having the highest at 38\%, which 
causes it to pool water due to the high solubility of sylvite. AG Bypass High contains $11 \%$, while AG Wet contains only trace amounts, causing a lower water to solid ratio compared to AG Bypass Low.

The study found the major product in the carbonation of these three CKD types to be calcium carbonate $\left(\mathrm{CaCO}_{3}\right)$ in both crystalline and amorphous form in all CKD types. The dominant reaction path was the carbonation of $\mathrm{CaO}$ and $\mathrm{Ca}(\mathrm{OH})_{2}$. A second reaction path is the weathering of Ca-silicates to release $\mathrm{Ca}^{2+}$ for carbonation. This second path is a minor contributor due to the small amount of Ca-silicates present and the longer reaction times for their carbonation.

The carbonation of $\mathrm{CaO}$ and $\mathrm{Ca}(\mathrm{OH})_{2}$ was found to occur through three different precipitation mechanisms. These mechanisms were influenced by the amount of water present in the reactions and the characteristics of the CKD type. In the AG Bypass High $\mathrm{CKD}, \mathrm{CaO}$ was present at a $36 \%$ (dry weight) and combined with a low water to solid ratio $(<1: 1)$. The combination resulted in the diffusion of $\mathrm{CO}_{2}$ into the porous $\mathrm{Ca}(\mathrm{OH})_{2}$ particles and the precipitation of $\mathrm{CaCO}_{3}$ in the pores of the particles. A carbonate-rich ring formed on the outside of the particles and grew inward with time. However, this ring may slow vapor and aqueous diffusion by causing blockages in the pore systems.

Evidence was found in the AG Wet samples that may support this mechanism in that CKD type as well.

The second observed precipitation mechanism involved precipitation of $\mathrm{CaCO}_{3}$ through nucleation with existing particles is also possible in all CKD types. The AG Bypass Low had a high water to solid ratio $(>>1: 1)$ due to its sylvite content (at least $38 \%$ (dry weight)). This allowed for more $\mathrm{Ca}(\mathrm{OH})_{2}$ dissolution, which led to carbonate 
precipitation from saturated aqueous solution as the sample was dried. This third precipitation mechanism was only observed in the AG Bypass Low due to its higher water to solid ratio caused by its sylvite content.

The chemical equilibrium experiments showed a decrease in solubility in $\mathrm{Cr}, \mathrm{Pb}$, and $\mathrm{Cu}$ due to carbonation. The PHREEQC geochemical modeling showed that $\mathrm{CaO}$ and $\mathrm{Ca}(\mathrm{OH})_{2}$ would be fully carbonated to $\mathrm{CaCO}_{3}$ if full equilibrium with $\mathrm{CO}_{2}$ was reached. This supports the hypothesis regarding reactants and products in the carbonation reactions. Although the laboratory experiments did not reach equilibrium with $\mathrm{CO}_{2}$, it gave insight to $\mathrm{Ca}$ solubility changes due to $\mathrm{pH}$ and showed a decrease in metals solubility due to carbonation.

Overall, this study has provided insight in to the reactants and products and the nature of the precipitation reactions occurring in the carbonation of three types of CKD. These results show that precipitation mechanisms may be slowing the rate of carbonation and possibly preventing full carbonation from occurring. Carbonate precipitation may cause blockage pores within reactive particles such that diffusion of $\mathrm{CO}_{2}$ into these particles is slowed sufficiently to inhibit complete carbonation. Decreases (40-90\%) in lead, chromium, and copper leaching due to carbonation were also observed.

\section{RECOMMENDATIONS}

For better microscopic analyses, the CKD could be separated into several size ranges prior to carbonation. Division by particle size allow for determination of composition distribution by particle size and may show higher carbonation for small particle size due to increased lime content in smaller particles. SEM-EDX analysis of samples of the same particle size would allow for better characterization of 
morphological changes and measurements of the carbonate rings found in the AG Bypass High.

Altering the time of carbonation for both the ESEM particle comparison and SEM-EDX microanalysis would provide greater insight into the precipitation mechanisms. Examination of particle comparisons in 4 hour steps for the first 24 to 48 hours should provide more information on carbonate precipitation mechanisms. Additional work with SEM-EDX microanalysis using batch reacted samples at similar reaction times would produce complementary cross-sectional analysis to allow better characterization of the precipitation mechanisms.

Further analysis of CKD that has been carbonated for longer times ( 8 to 16 days or more) especially of the AG Bypass High, would be beneficial to determine the extent of the carbonate rings and depletion of calcium silicates.

Development of a dependable way to incorporate the SEM-EDX into the direct particle comparison conducted on ESEM would provide better identification of the precipitate compositions seen in ESEM. This may involve different preparation techniques or carbon coating of reacted stubs for generalized elemental analysis. Although cross sectional EDX analysis is not possible in the direct particle comparison, conducting some EDX analysis on these stubs may allow for more certainty in the morphological and mineralogical changes occurring due to carbonation.

More investigation is needed in the metals mobility experiments since equilibrium was not reached. Longer laboratory mixing times should be used along with periodic $\mathrm{pH}$ testing. Possible comparison could be done by using a completely closed system for the 
virgin $\mathrm{CKD}$ and a system where $\mathrm{CO}_{2}$ is bubbled into the water for the carbonated $\mathrm{CKD}$. This could allow additional carbonation and would enable full equilibrium with $\mathrm{CO}_{2}$. TCLP (toxicity characteristic leaching procedure) testing as required by the EPA should be conducted on virgin and carbonated samples to determine the changes in leaching due to carbonation. Confirming lower metals solubility may contribute to the use of carbonation as a stabilization method for CKD. 


\section{REFERENCES}

Bertos, M.F., Li, X., Simons, S.J.R., Hills, C.D., and Carey, P.J. (2004a). Investigation of accelerated carbonation for the stabilization of MSW incinerator ashes and the Sequestration of $\mathrm{CO}_{2}$. Green Chemistry, 6:428-436.

Bertos, M.F., Simons, S.J.R., Hills, C.D., and Carey, P.J. (2004b). A review of accelerated carbonation technology in the treatment of cement-based materials and sequestration of $\mathrm{CO}_{2}$. Journal of Hazardous Materials, B112: 193-205.

Butt, D.P., Lackner, K.S., Wendt, C. H., Nomura, K., and Yanagisawa, Y. (1999). The Importance of and a Method for Disposing of Carbon Dioxide in a Thermodynamically Stable Form. World Resources Review, 11(2):196-219.

Chung, F.H. and Smith, D.K.(Eds.). (2000). Industrial Application of X-ray Diffraction. New York: Marcel Dekker. p. 21-25.

Corish, A., and Coleman, T. 1995. Cement Kiln Dust. Concrete, September/October 1995.

Department of Energy - National Energy Technology Laboratory (DOE-NETL) (2006). Carbon Sequestration Technology Roadmap and Program Plan 2005. [cited June1, 2006]. Available from: http://www.netl.doe.gov/publications/carbon_seq/2006_roadmap_for_web.pdf

Ecke, H. (2003). Sequestration of Metals in Carbonated Municipal Solid Waste Incineration (MSWI) Fly Ash. Waste Management, 23:631-640.

Falkowski, P., Scholes, R.J., Boyle, E., Canadell, J., Canfield, D., Elser, J., Gruber, N., Hibbard, K., Högberg, .P., Linder, S., Mackenzie, F.T., Moore, B. III, Pedersen, T., Rosenthal, Y., Seitzinger, G., Smetacek, V., and Steffen, W. (2000). The global Carbon Cycle: A Test of Our Knowledge of Earth as a System. Science, 290: 291-296.

Fauth, D.J., Baltrus, J.P., Soong, Y., Knoer, J.P., Howard, B.H., Graham, W.J., MarotoValer, M.M., and Andrésen, J.M. (2002). "Carbon Storage and Sequestration as Mineral Carbonates.” In M.M. Maroto-Valer, C. Song, and Y Soong (eds.), Environmental Challenges and Green House Gas Control for Fossil Fuel Utilization in the $21^{\text {st }}$ Century. (pp. 1-17). Kluwer Academic / Plenum Publishers.

Guthrie, G.D., J.W. Carey, D. Bergfeld, D. Byler, S. Chipera, H.J. Ziock, and K.S. Lackner. (2001). Geochemical Aspects of the Carbonation of Magnesium Silicates in an Aqueous Medium. National Energy Technology Laboratory Conference on Carbon Sequestration.

Halim, C.E., Short, S.A., Scott, J.A., Amal, R., and Low, G. (2005). Modelling the leaching of $\mathrm{Pb}, \mathrm{Cd}, \mathrm{As}$, and $\mathrm{Cr}$ from cementitious waste using PHREEQC. Journal of Hazardous Materials, A125:45-61.

Huijgen, W.J.J., Witkamp, G., and Comans, R.N.J. (2005). Mineral $\mathrm{CO}_{2}$ Sequestration by Steel Slag Carbonation. Environmental Science and Technology, 39(24):96769682. 
Huijgen, W.J.J. and Comans, R.N.J. (2006). Carbonation of Steel Slag for $\mathrm{CO}_{2}$ Sequestration: Leaching of Products and Reaction Mechanisms. Environmental Science \& Technology 40, 8:2790-2796.

Huntzinger, D. N., Gierke, J. S., Kawatra, K., Eisele, T. C., and Sutter, L. L. (2006a). Carbon Dioxide Sequestration in Cement Kiln Dust through Mineral Carbonation. Unpublished Manuscript, Michigan Technological University, Houghton, Michigan.

Huntzinger, D. N., Gierke, J. S., Kawatra, K., Eisele, T. C., and Sutter, L. L. (2006b). Mineral Carbonation for Carbon Sequestration in Cement Kiln Dust from Waste Piles. In Progress, Michigan Technological University, Houghton, Michigan.

Klemm, W.A. 1994. What are CKD Uses and Characteristics? Rock Products Cement Edition July 1994: 38-44

Klug, H. P. and Alexander, L. E. (1974). X-ray Diffraction Procedures, 2nd edition, New York: John Wiley and Sons

Lackner, K.S., D.P. Butt, and C.H. Wend. (1997). Progress on Binding $\mathrm{CO}_{2}$ in Mineral Substrates. Energy Conversion and Management, 38:259-264.

Meima, J.A.,van der Weijden, R. D., Eighmy, T.T., and Comans, R.N.J. (2002). Carbonation processes in municipal solid waste incinerator bottom ash and their effect on the leaching of copper and molybdenum. Applied Geochemistry, 17:1503-1513.

Peterson, K. R. (2006). Personal Communications. 1400 Townsend Drive Houghton, MI 49931-1295 USA.

Sreekrishnavilasam, A., Kings, S., and Santagata, M. (2006). Characterization of fresh and landfilled cement kiln dust for reuse in construction applications. Engineering Geology, 85:165-173.

Steinour, H. H. (1959). Some Effects of Carbon Dioxide on Mortars and Concrete Discussion. Journal of the American Concrete Institute, 30: 905-907.

Taylor, H.F.W. (1997). Cement Chemistry. ( $2^{\text {nd }}$ ed.). London: Thomas Telford.

United States Geological Survey (USGS). (1998). PHREEQCI - A graphical user interface for the geochemical computer program PHREEQC. [cited May 7, 2006]. Available from: http://wwwbrr.cr.usgs.gov/projects/GWC_coupled/phreeqci/

University of Wisconsin - Madison (UWM) Soil \& Plant Analysis Laboratory. (2004).

Soil pH and SMP Lime Requirement. Available at: http://uwlab.soils.wisc.edu/files/procedures/pH_SMP.pdf

University of Wisconsin - Madison (UWM) Soil \& Plant Analysis Laboratory (2005a). Standard Operation Procedure Elemental Analysis of Solution samples with Inductively Coupled Plasma Mass Spectrometry. Available at: http://uwlab.soils.wisc.edu/files/procedures/ICPMS.pdf 
University of Wisconsin - Madison (UWM) Soil \& Plant Analysis Laboratory (2005b) Standard Operation Procedure Elemental Analysis of Solution Samples with Inductively Coupled Plasma Optical Emission Spectrometry. Available at: http://uwlab.soils.wisc.edu/files/procedures/ICPOES.pdf

Van Gerven, T., Van Keer, E., Arickx, S., Jaspers, M., Wauters, G., and Vandecasteel, C. (2005). Carbonation of MSEI-bottom ash to decrease heavy metal leaching in view of recycling. Waste Management, 25:291-300.

van Oss H. B. and Padovani, A.C. (2003). Cement Manufacture and the Environment Part 2: Environmental Challenges and Opportunities. Journal of Industrial Ecology, 7(1):93-126.

Walenta, G., Füllmann, T., and Gimenes, M. (2001). Quantitative Rietveld analysis of cement and clinker. International Cement Review, June:51-54.

Wolf, G.H., Chizmeshya, A.V.G., Diefenbacher, J., and McKelvy, M.J. (2004). In Situ Observation of $\mathrm{CO}_{2}$ Sequestration Reactions Using a Novel Microreaction System. Environmental Science and Technology, 38(3):932-936. 


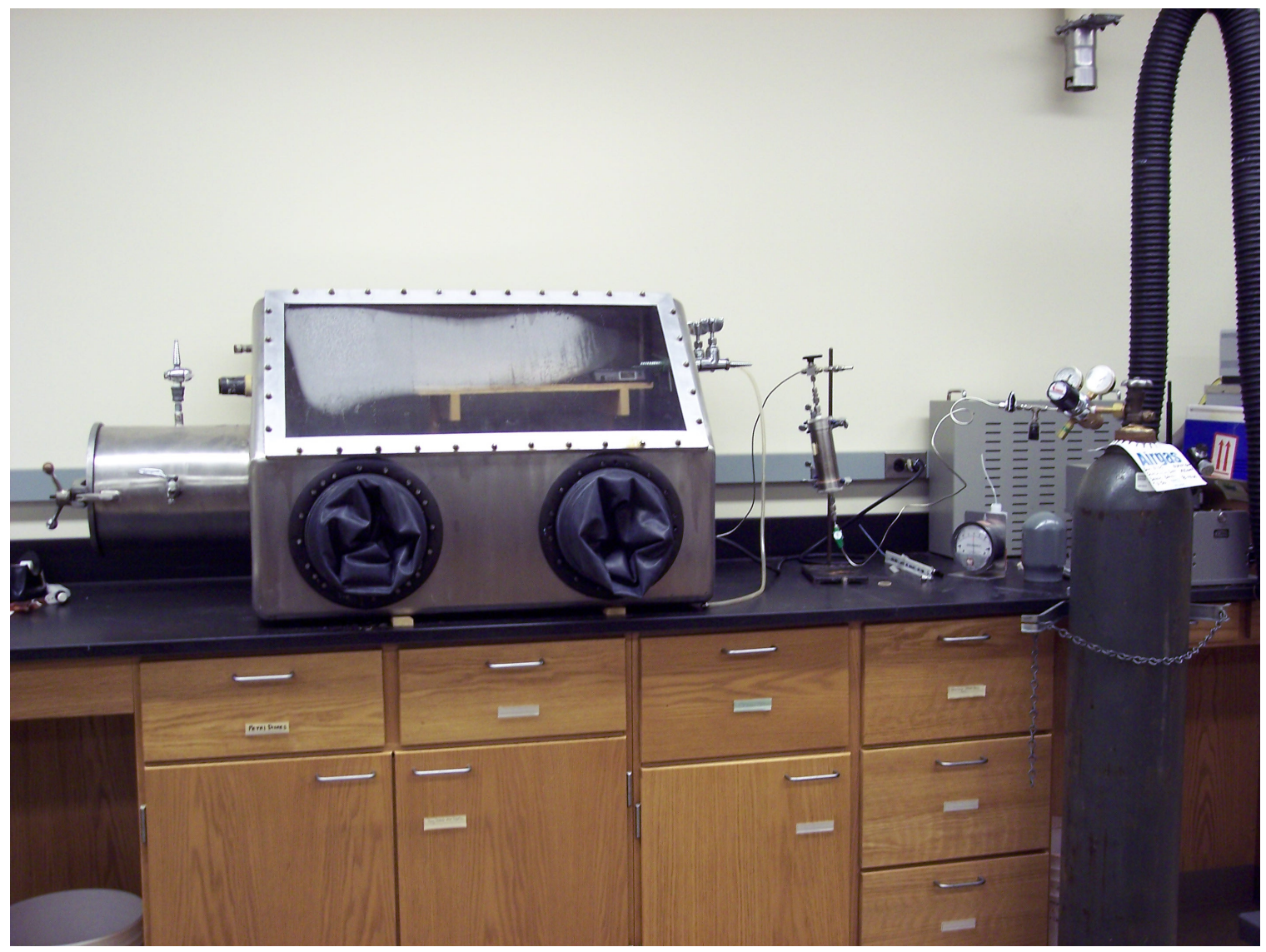

Figure 1: The reaction box used to carbonate cement kiln dust samples was connected to a pure-CO2 tank. $\mathrm{CO} 2$ was first passed through distilled/deionized (DI) water prior to entering the box, which contained a pan of DI water and a humidity monitor. CO2 concentrations were monitored by twice-daily air samples run through a gas chromatograph. 


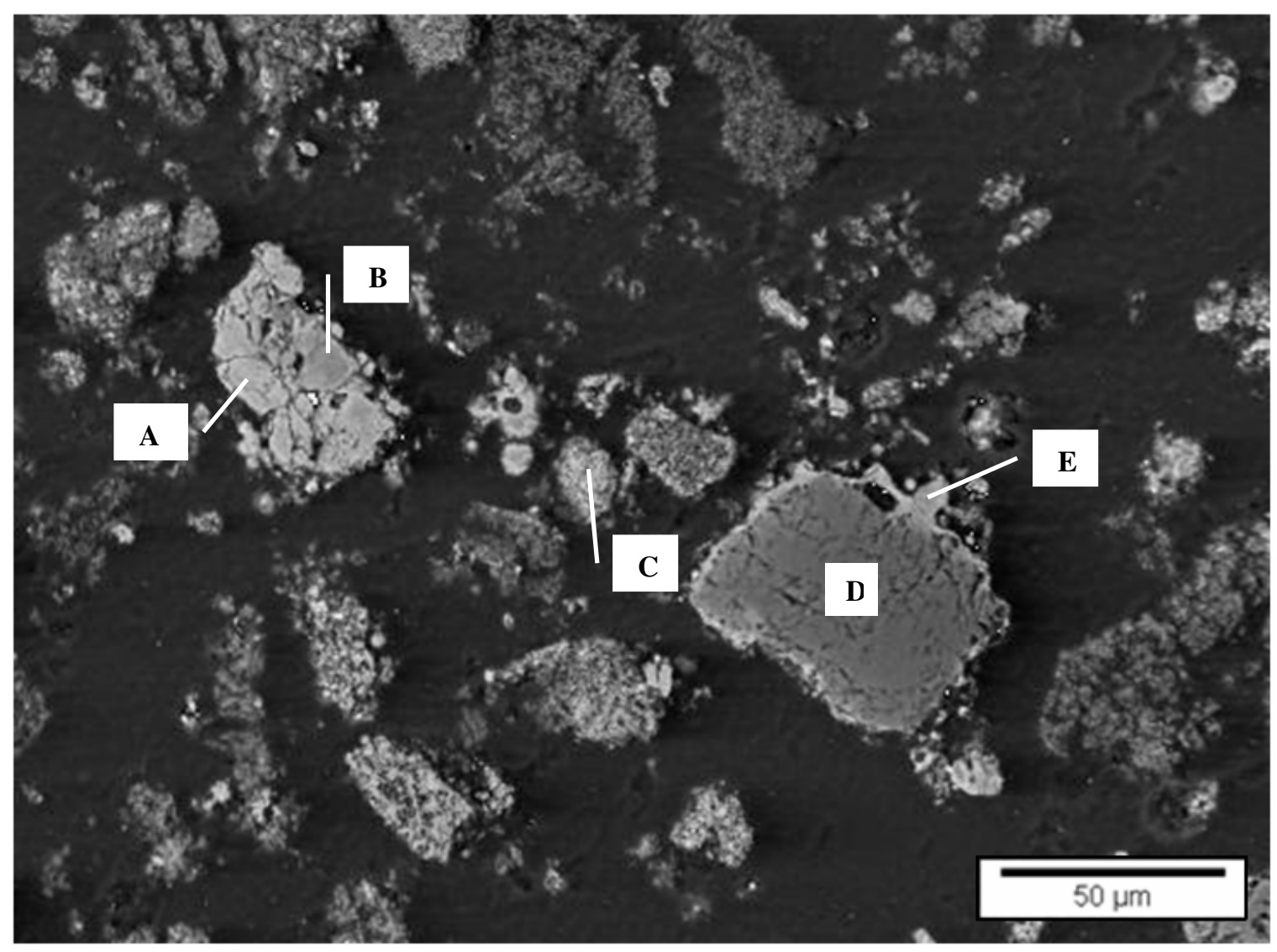

Figure 2: Area mapped for the Virgin Ash Grove Bypass High showing the locations that were analyzed using energy dispersive $\mathrm{x}$-ray microanalysis. The energy dispersive $\mathrm{x}$-ray results are summarized in Table 3. 


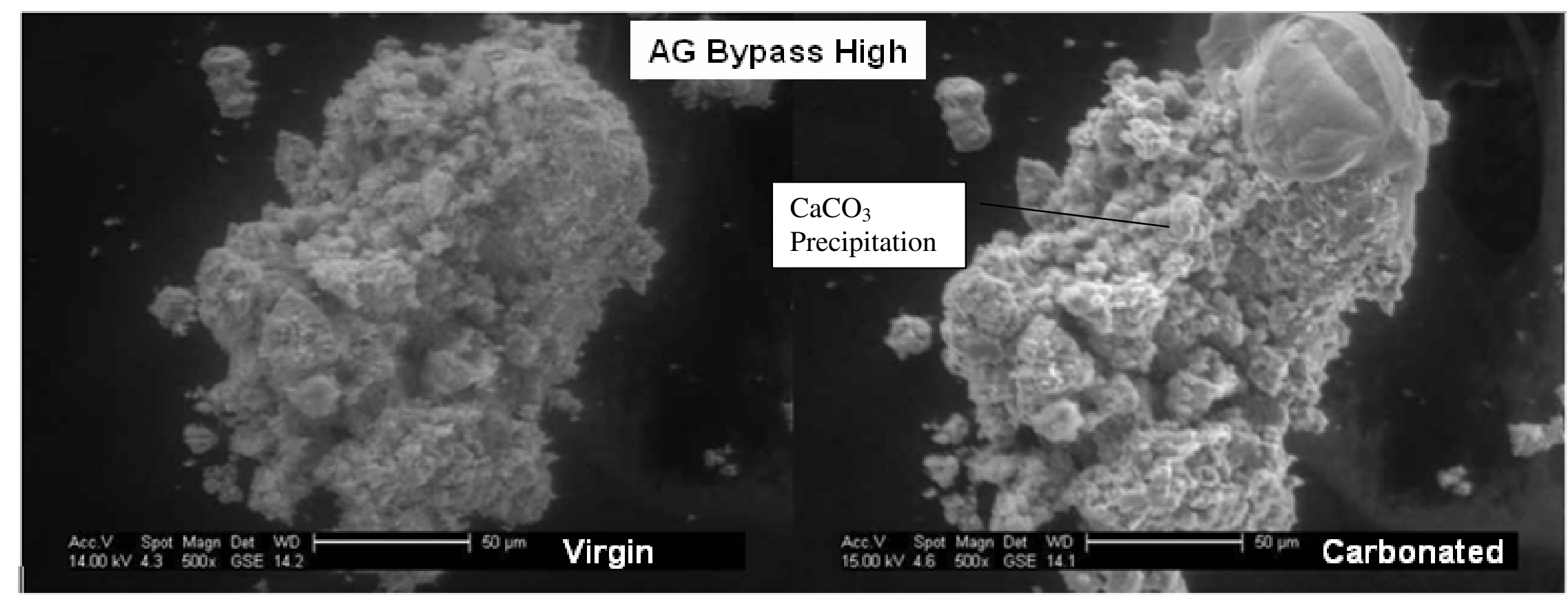

Figure 3: Direct comparisons of an AG Bypass High cement kiln dust particle conducted by environmental scanning electron microscopy. The increased clarity of the image of the carbonated form is due to the precipitation of carbonates, which have higher density than oxides. 


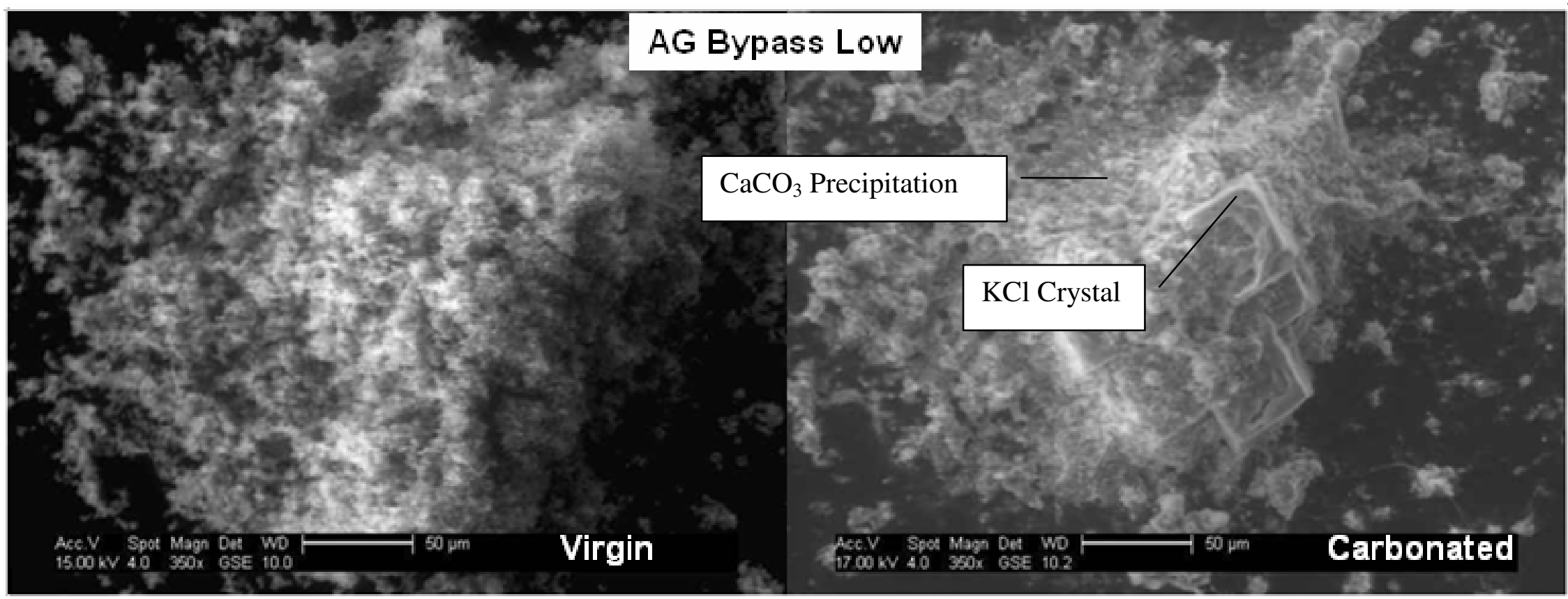

Figure 4: Direct comparison of Ash Grove Bypass Low particle conducted by environmental scanning electron microscopy and showing the formation of sylvite $(\mathrm{KCl})$ crystals along with $\mathrm{CaCO}_{3}$ precipitation. 


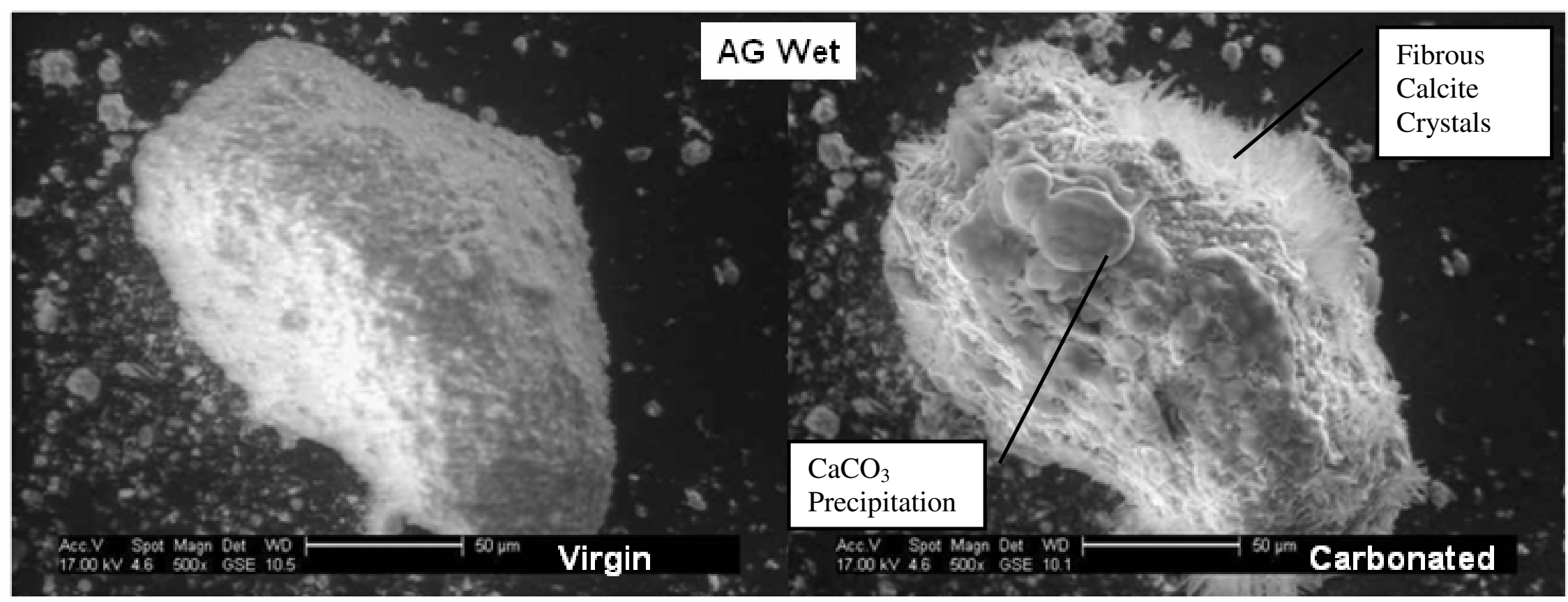

Figure 5: Direct comparison of Ash Grove Wet particle conducted by environmental scanning electron microscopy and showing the formation of fibrous calcite crystals along with $\mathrm{CaCO}_{3}$ precipitation 


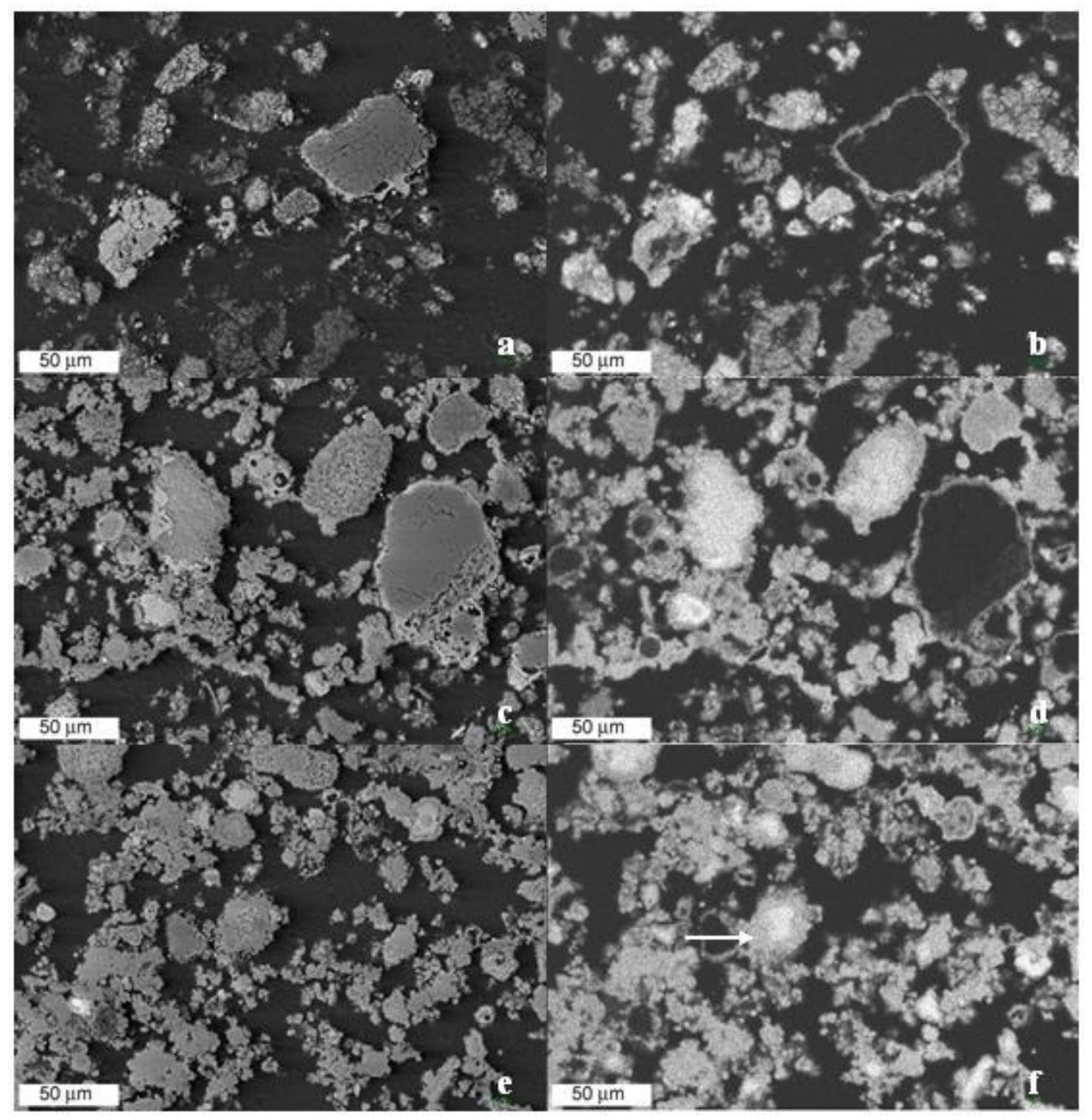

Figure 6: Backscattered electron images (left) and the results of calcium (Ca) mapping by energy dispersive X-ray (right) on the AG Bypass High cement kiln dust. The bright white represent the highest calcium content and black represents the absence of $\mathrm{Ca}$. Figures 6a-b are of virgin cement kiln dust, 6c-d are 8-hour reacted cement kiln dust, and 6e-f are 4-day reacted cement kiln dust. The $\mathrm{Ca}$ content, corresponding to the carbonation of free lime and portlandite, appears to increase over time. The highlighted particle in $6 f$ corresponds to the particle displayed in Figure 8b. 

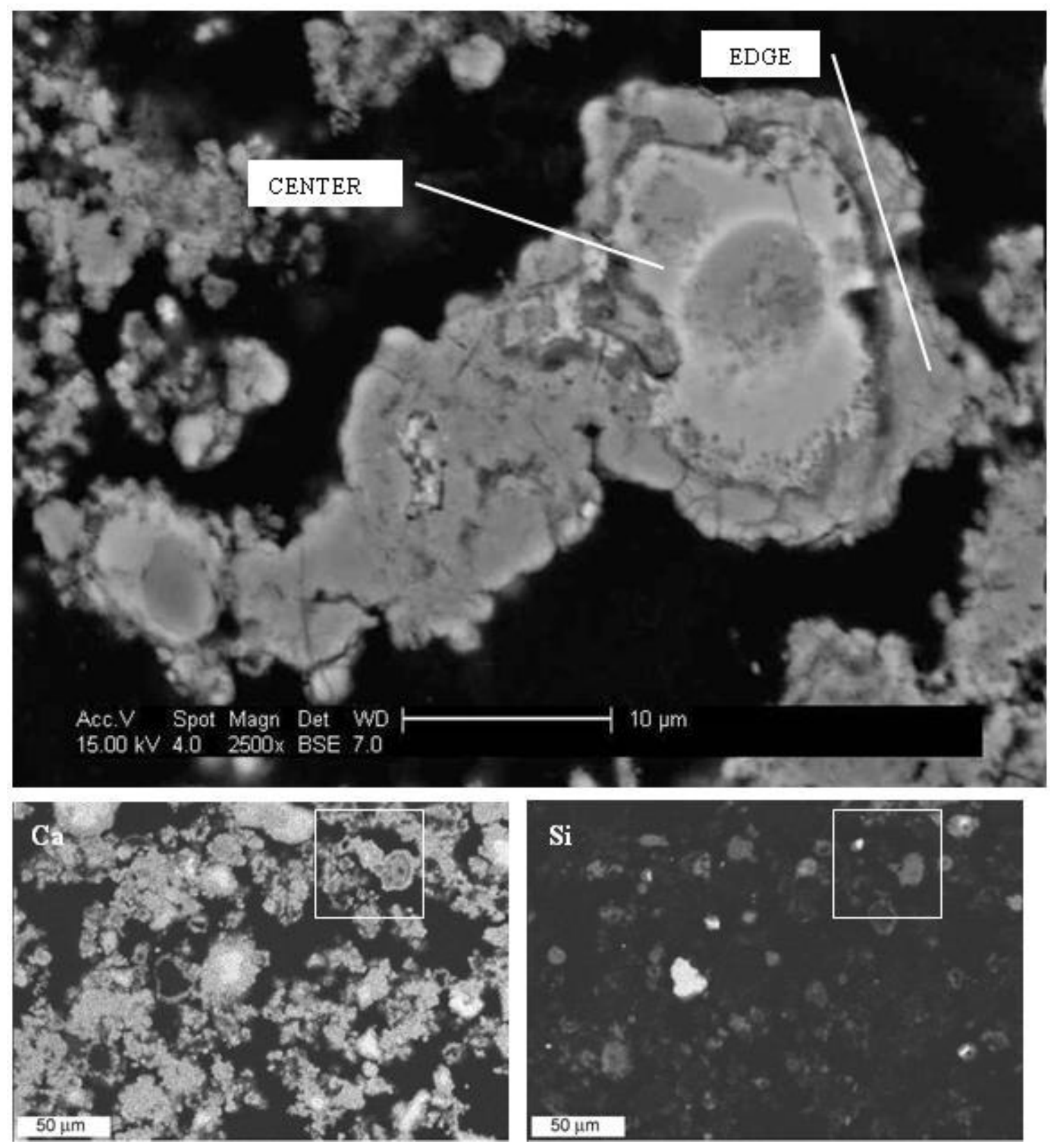

Figure 7: Ash Grove Bypass High Particle with depleted calcium silicate center and precipitate $\mathrm{CaCO}_{3}$ on the edge. Corresponding calcium (Ca) and silicon ( $\mathrm{Si}$ ) maps are shown with the zoomed particle outlined. The presence of $\mathrm{Si}$ is evident in the low $\mathrm{Ca}$ content center. The particle shows the average composition with standard deviations obtained from energy dispersive $\mathrm{x}$-ray microanalysis for the center and edge of this particle (Table 4). 

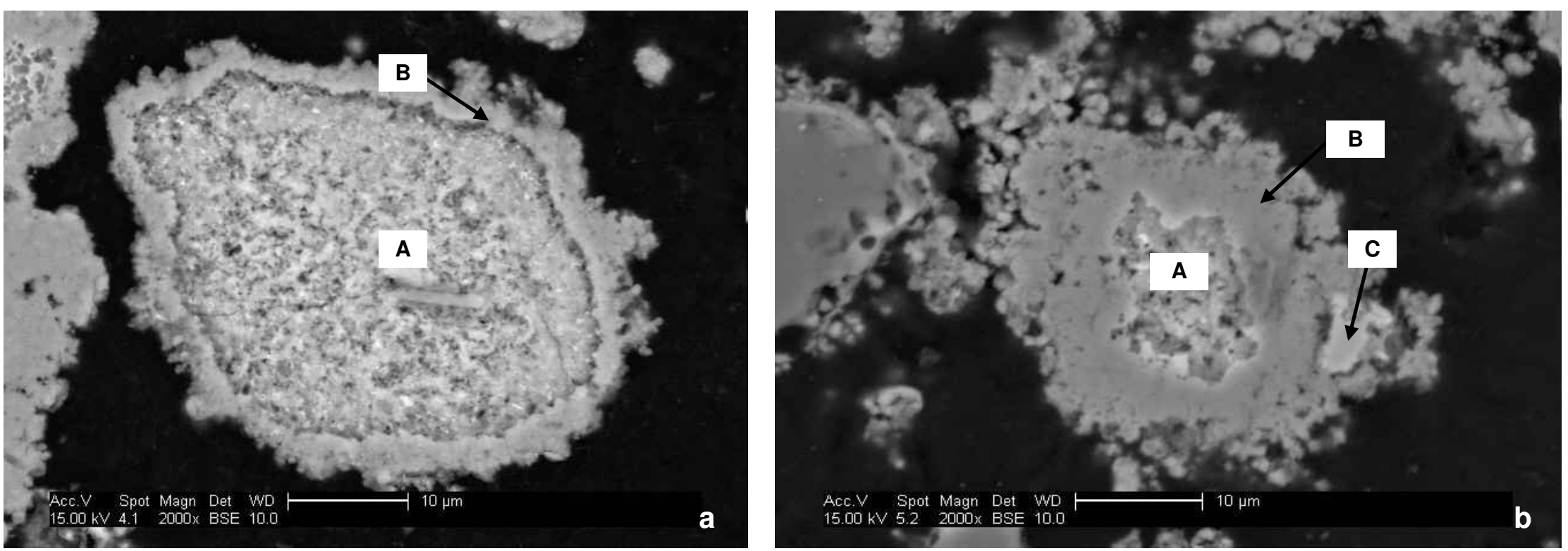

Figure 8: Backscatter electron images of particles of 4-day Ash Grove Bypass High exhibiting different degrees of carbonations: (a) particle with limited calcite (B) rim around portlandite (A) center, (b) particle with larger calcite (B) rim and smaller portlandite (A) center suggesting greater carbonation. Table 6 provides five detailed, elemental composition of labeled areas. 

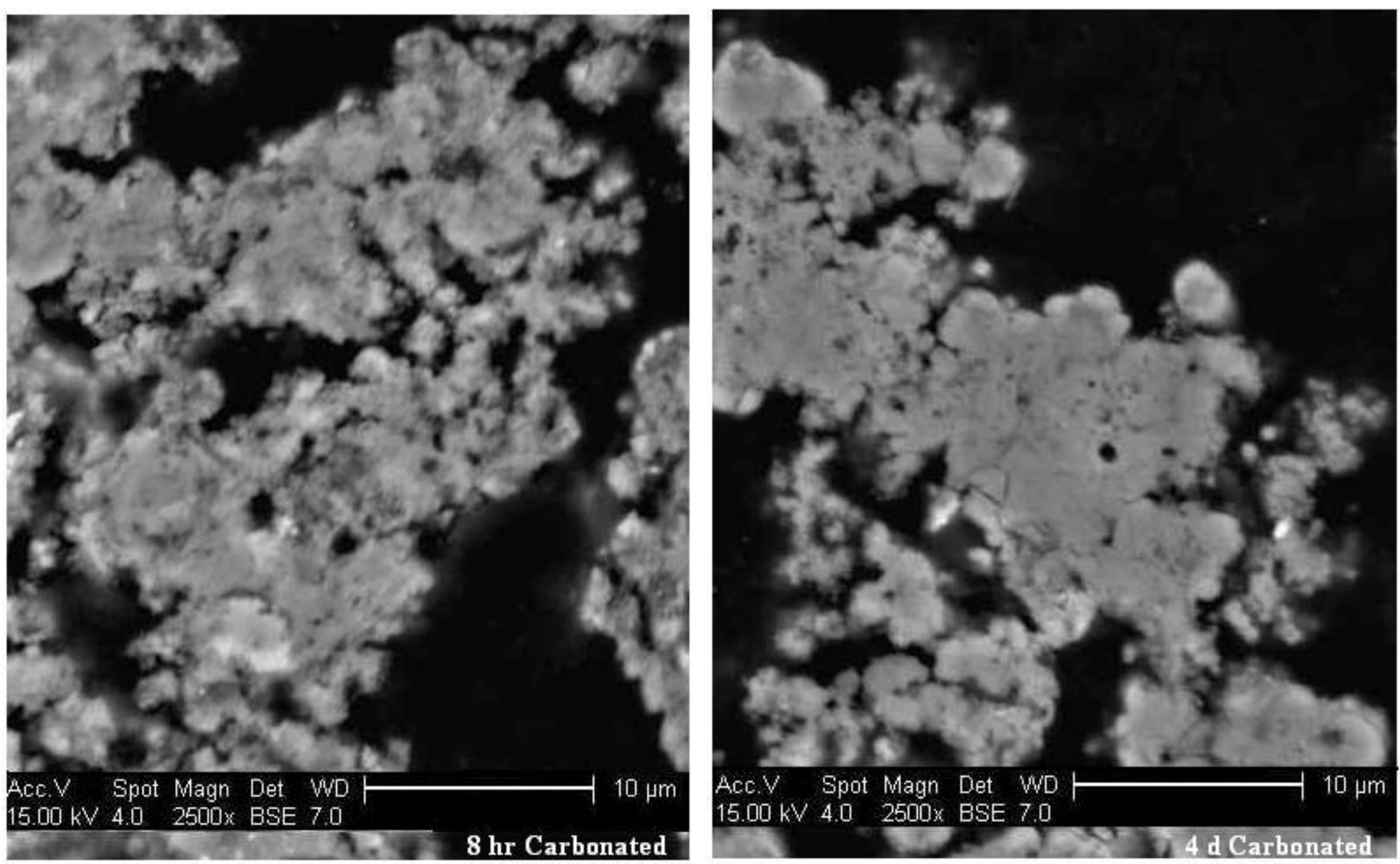

Figure 9: Backscattered electron images of two examples of carbonate precipitation in 8-hour and 4-day carbonated Ash Grove Bypass High. Both have calcium contents of $37 \%$ (dry weight) and are similar in shape and color. Table 7 lists the energy dispersive $\mathrm{x}$-ray elemental microanalysis data for these particles. 


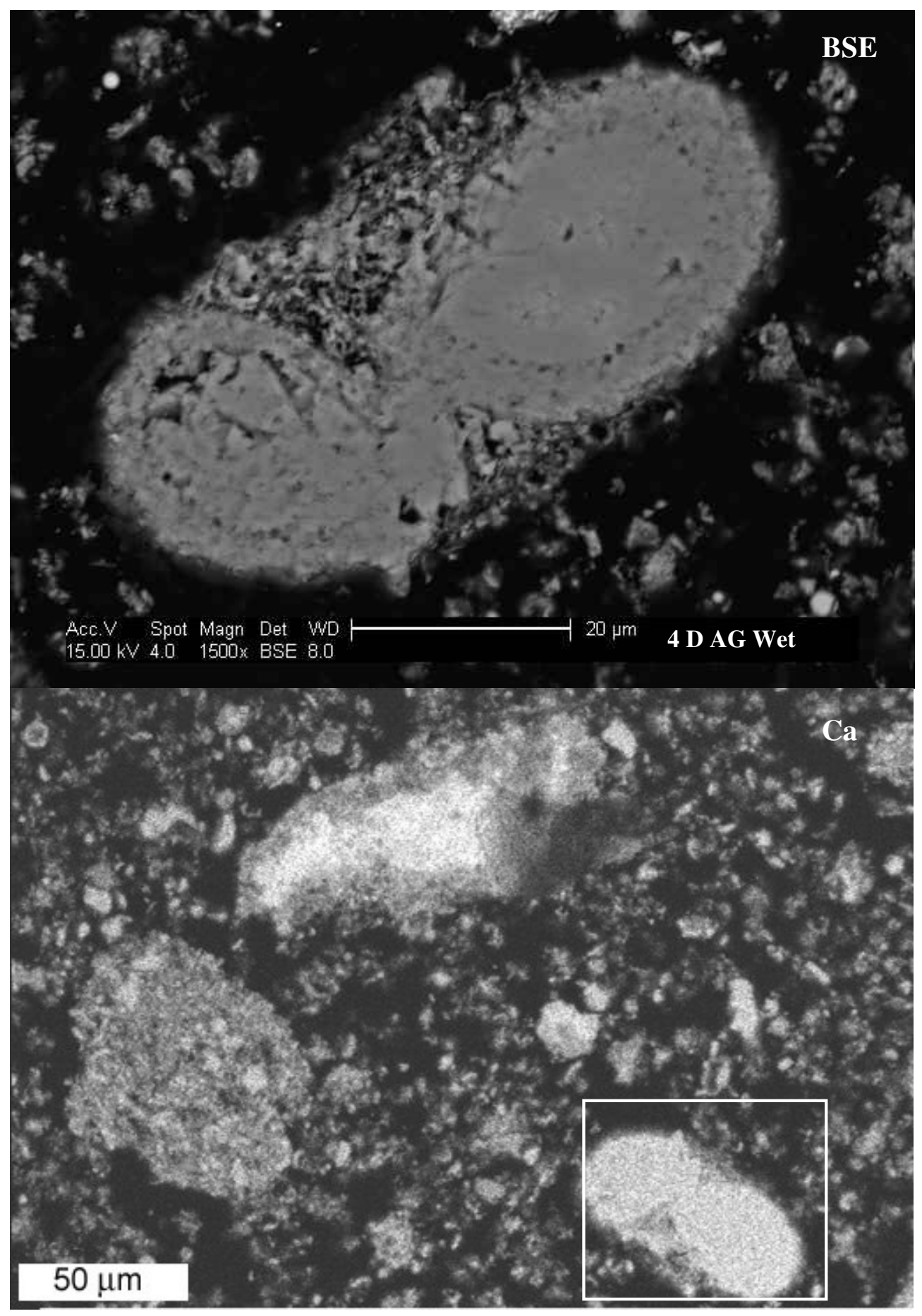

Figure 10: Backscattered electron (BSE) image of a particle of $\mathrm{CaCO}_{3}$ in 4-day carbonated samples of Ash Grove Wet. Particle composition (see Table 8) is $\mathrm{CaCO}_{3}$. The calcium (Ca) content map (lower) shows constant calcium content for this particle (see boxed area). The altered edge is mostly likely newly precipitated $\mathrm{CaCO}_{3}$, while the center was present in the virgin cement kiln dust and acted as a nucleus to precipitation. 


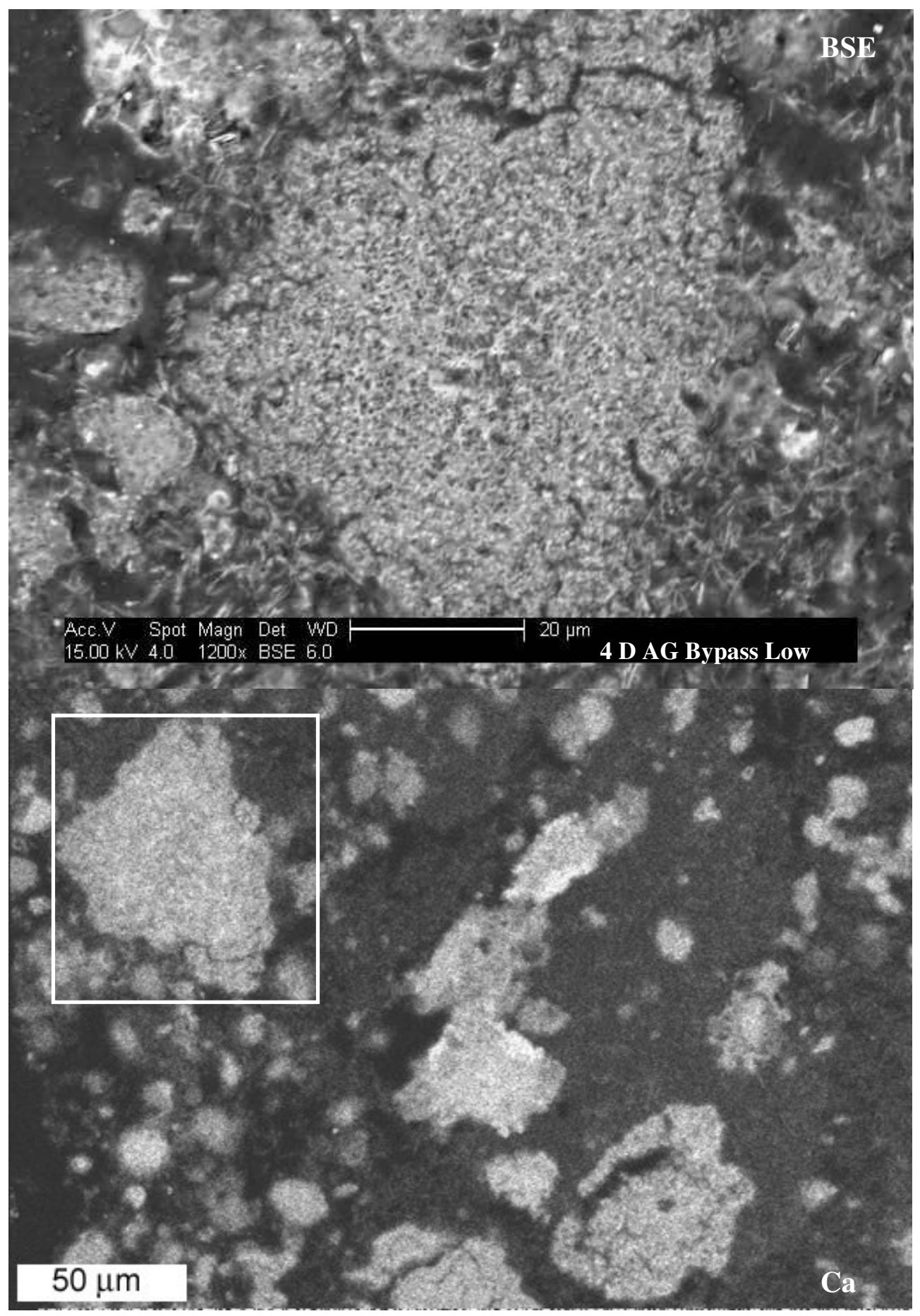

Figure 11: Back scattered electron (BSE) image of a particle of 4-day Ash Grove Bypass Low, with a composition (see Table 8) of $\mathrm{CaCO}_{3}$. The accompanying calcium map shows a relatively uniform distribution of calcium throughout the particle. 

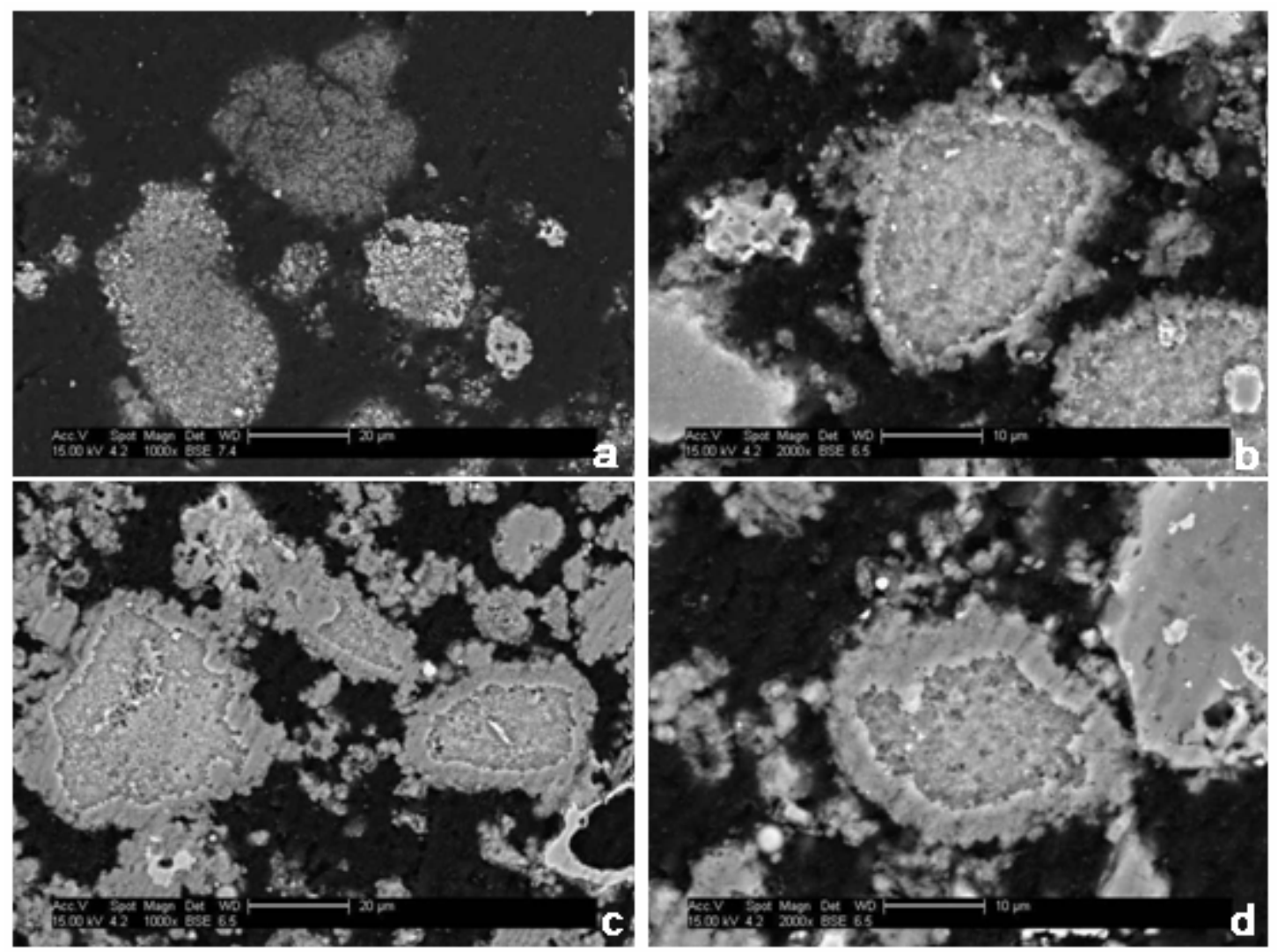

Figure 12: Back scattered electron images of Ash Grove Bypass High: (a) virgin (noncarbonated) cement kiln dust, (b) 8-hour reacted cement kiln dust, and (c-d) 4-day reacted cement kiln dust. Figure 12a show virgin candidates for these $\mathrm{Ca}(\mathrm{OH})_{2}$ centers. $\mathrm{CaCO}_{3}$ rings forming around $\mathrm{Ca}(\mathrm{OH})_{2}$ centers are evident in $4 \mathrm{~b}-\mathrm{d}$ with the rings growing in thickness over time. 
Table 1: Composition (\% dry weight) of the cement kiln dust samples analyzed in this study based on x-ray fluorescence spectrometry, which yields mineral compositions in terms of oxide.

\begin{tabular}{|c|c|c|c|}
\hline Oxide & $\begin{array}{c}\mathrm{AG}^{¥} \text { Bypass } \\
\text { High }\end{array}$ & $\begin{array}{c}\mathrm{AG}^{¥} \text { Bypass } \\
\text { Low }\end{array}$ & $\mathrm{AG}^{¥}$ Wet \\
\hline $\mathrm{Na}_{2} \mathrm{O}$ & 0.65 & 1.83 & 0.49 \\
\hline $\mathrm{MgO}$ & 1.39 & 0.52 & 0.55 \\
\hline $\mathrm{Al}_{2} \mathrm{O}_{3}$ & 3.45 & 1.59 & 4.09 \\
\hline $\mathrm{SiO}_{2}$ & 13.31 & 5.09 & 12.61 \\
\hline $\mathrm{P}_{2} \mathrm{O}_{5}$ & 0.06 & 0.04 & 0.11 \\
\hline $\mathrm{K}_{2} \mathrm{O}$ & 7.04 & 24.04 & 4.03 \\
\hline $\mathrm{CaO}$ & 48.03 & 22.72 & 47.14 \\
\hline $\mathrm{TiO}_{2}$ & 0.23 & 0.12 & 0.22 \\
\hline $\mathrm{MnO}$ & 0.06 & 0.03 & 0.13 \\
\hline $\mathrm{Fe}_{2} \mathrm{O}_{3}$ & 2.14 & 1.16 & 1.79 \\
\hline $\mathrm{SO}_{3}$ & 2.73 & 5.78 & 7.66 \\
\hline $\mathrm{Cl}^{-}$ & 5.22 & 20.41 & 0.18 \\
\hline $\mathrm{Br}^{-}$ & 0.21 & 1.03 & 0.03 \\
\hline LOI $^{*}$ & 14.88 & 15.07 & 20.37 \\
\hline Total & 99.39 & 99.43 & 99.4 \\
\hline
\end{tabular}

$¥$ Samples provided by Ash Grove Cement Company

${ }^{*}$ Loss on Ignition 
Table 2: Results of normative calculations of compositions for the three cement kiln dust types examined in this study. Data from xray fluorescence spectrometry data (Table 1), qualitative x-ray diffraction, and thermogravimetric analysis (Huntzinger et al. 2006a) were used in this calculation.

\begin{tabular}{|c|c|c|c|c|}
\hline & & AG ${ }^{\ddagger}$ Bypass High & AG ${ }^{\ddagger}$ Bypass Low & $\mathbf{A G}^{\ddagger}$ Wet \\
\hline Mineral & Formula & $\mathrm{wt} \%$ & $\mathrm{wt} \%$ & $\mathrm{wt} \%$ \\
\hline Anhydrite $^{\mathrm{a}}$ & $\mathrm{CaSO}_{4}$ & 4.6 & 9.8 & 13.0 \\
\hline Calcite $^{\text {b }}$ & $\mathrm{CaCO}_{3}$ & 9.4 & 2.6 & 32.5 \\
\hline Halite & $\mathrm{NaCl}$ & 1.2 & 3.5 & 0.0 \\
\hline (Available) Lime ${ }^{c}$ & $\mathrm{CaO}$ & 36.4 & 10.8 & 21.9 \\
\hline Portlandite & $\mathrm{Ca}(\mathrm{OH})_{2}$ & 5.9 & 8.5 & 2.2 \\
\hline Quartz & $\mathrm{SiO}_{2}$ & 13.3 & 5.1 & 12.6 \\
\hline Sylvite & $\mathrm{KCl}$ & 11.1 & 38.0 & 0.0 \\
\hline Potassium Oxide $^{\mathrm{d}}$ & $\mathrm{K}_{2} \mathrm{O}$ & 0.0 & 0.0 & 4.0 \\
\hline Sodium Oxide $^{\mathrm{d}}$ & $\mathrm{Na}_{2} \mathrm{O}$ & 0.0 & 0.0 & 0.5 \\
\hline \multicolumn{2}{|l|}{ LOI* $^{*}$} & 14.9 & 15.1 & 20.4 \\
\hline \multicolumn{2}{|l|}{ Total Percentage } & 96.9 & 93.4 & 107.1 \\
\hline
\end{tabular}

${ }^{¥}$ Samples provided by Ash Grove Cement Company

${ }^{\text {a }}$ Calculations assumed anhydrite was the only $\mathrm{SO}_{3}$ containing species.

${ }^{\mathrm{b}}$ Calculations used calcite percentage obtained from $\mathrm{x}$-ray diffraction using the relative intensity ratio method.

${ }^{\mathrm{c}}$ Calculated assuming calcite, anhydrite, and portlandite were the only other $\mathrm{CaO}$ containing species meaning the remaining $\mathrm{CaO}$ would be available for carbonation.

${ }^{\mathrm{d}}$ Results from $\mathrm{X}$-ray diffraction using relative intensity ratio did not show $\mathrm{K}_{2} \mathrm{O}$ or $\mathrm{Na}_{2} \mathrm{O}$ containing species present in AG Wet, direct $\mathrm{x}$-ray fluorescence spectrometry percentages are shown.

* Loss on Ignition 
Table 3: Energy dispersive x-ray elemental microanalysis data (\% dry weight) for virgin (noncarbonated) Ash Grove Bypass High. Data corresponds to areas labeled on Figure 2.

\begin{tabular}{|c|c|c|c|c|c|c|c|c|c|c|}
\hline Location & \multicolumn{2}{|c|}{$\mathbf{A}$} & \multicolumn{2}{|c|}{ B } & \multicolumn{2}{|c|}{$\mathbf{C}$} & \multicolumn{2}{|c|}{$\mathbf{D}$} & \multicolumn{2}{|c|}{$\mathbf{E}$} \\
\hline Element & Average & $\begin{array}{l}\text { Standard } \\
\text { Deviation }\end{array}$ & Average & $\begin{array}{l}\text { Standard } \\
\text { Deviation }\end{array}$ & Average & $\begin{array}{l}\text { Standard } \\
\text { Deviation }\end{array}$ & Average & $\begin{array}{l}\text { Standard } \\
\text { Deviation }\end{array}$ & Average & $\begin{array}{l}\text { Standard } \\
\text { Deviation }\end{array}$ \\
\hline $\mathrm{Na}$ & 0.3 & 0.4 & 0.5 & 0.1 & 0.4 & 0.1 & 0 & 0 & 1.3 & 0.4 \\
\hline $\mathrm{Mg}$ & 0.8 & 0.2 & 0 & 0 & 0.5 & 0.1 & 0 & 0 & 0.5 & 0.3 \\
\hline $\mathrm{Al}$ & 6.5 & 1.7 & 13.4 & 0.6 & 0.3 & 0.1 & 0 & 0 & 7.9 & 3.1 \\
\hline $\mathrm{Si}$ & 15.1 & 1.3 & 21.3 & 0.6 & 0.5 & 0.1 & 43.9 & 0.9 & 19.1 & 2.9 \\
\hline $\mathrm{P}$ & 0 & 0 & 0 & 0 & 0.0 & 0.0 & 0 & 0 & 0 & 0 \\
\hline$S$ & 0 & 0 & 0 & 0 & 6.2 & 2.3 & 0 & 0 & 0.2 & 0.4 \\
\hline $\mathrm{Cl}$ & 0.1 & 0.1 & 0.2 & 0.1 & 0.7 & 0.2 & 0 & 0 & 0.8 & 1.3 \\
\hline $\mathrm{K}$ & 0.5 & 0.2 & 19.4 & 1.6 & 0.6 & 0.3 & 0 & 0.1 & 4.8 & 1.3 \\
\hline $\mathrm{Ca}$ & 37.8 & 5 & 6.4 & 2.4 & 49.3 & 2.9 & 0.1 & 0 & 23.3 & 2.5 \\
\hline $\mathrm{Mn}$ & 0.1 & 0.1 & 0 & 0 & 0.0 & 0.0 & 0 & 0 & 0 & 0 \\
\hline $\mathrm{Fe}$ & 3 & 1.2 & 1.8 & 0.5 & 0.2 & 0.4 & 0 & 0 & 3.3 & 1.3 \\
\hline Total & 64.1 & 2.8 & 63.2 & 1.4 & 58.7 & 5.2 & 44.1 & 0.9 & 61.1 & 4.2 \\
\hline $\mathrm{H}+\mathrm{O}+\mathrm{C}^{*}$ & 35.9 & 2.8 & 36.8 & 1.4 & 41.3 & 5.2 & 55.9 & 0.9 & 38.9 & 4.2 \\
\hline Mineral Type & \multicolumn{2}{|c|}{ Calcium Silicate } & \multicolumn{2}{|c|}{ Potassium Silicate } & \multicolumn{2}{|c|}{ Calcium Hydroxide } & \multicolumn{2}{|c|}{ Silica Oxide } & \multicolumn{2}{|c|}{ Calcium Silicate } \\
\hline $\begin{array}{l}\text { Mineral Name } \\
\text { (if known) }\end{array}$ & & & & & \multicolumn{2}{|c|}{ Portlandite } & \multicolumn{2}{|c|}{ Quartz } & & \\
\hline
\end{tabular}

* Difference between total and $100 \%$ is assumed to be the sum of hydrogen, oxygen, and carbon. 
Table 4: Energy dispersive x-ray elemental microanalysis data (\% dry weight) corresponding to labeled areas on the Ash Grove Bypass High particle shown in Figure 7.

\begin{tabular}{|l|r|r|r|r|}
\hline Location & \multicolumn{2}{|c|}{ Particle Center } & \multicolumn{2}{|c|}{ Particle Edge } \\
\hline Element & Average & $\begin{array}{l}\text { Standard } \\
\text { Deviation }\end{array}$ & Average & $\begin{array}{l}\text { Standard } \\
\text { Deviation }\end{array}$ \\
\hline $\mathrm{Na}$ & 1.6 & 0.2 & 1.1 & 0.3 \\
\hline $\mathrm{Mg}$ & 0.7 & 0.2 & 0.8 & 0.4 \\
\hline $\mathrm{Al}$ & 8.7 & 1.0 & 0.9 & 0.9 \\
\hline $\mathrm{Si}$ & 19.0 & 0.6 & 1.7 & 1.1 \\
\hline $\mathrm{P}$ & 0.0 & 0.0 & 0.1 & 0.1 \\
\hline $\mathrm{S}$ & 0.2 & 0.1 & 0.1 & 0.0 \\
\hline $\mathrm{Cl}$ & 0.2 & 0.1 & 0.3 & 0.1 \\
\hline $\mathrm{K}$ & 5.1 & 1.2 & 2.6 & 0.3 \\
\hline $\mathrm{Ca}$ & 24.3 & 1.1 & 34.6 & 1.6 \\
\hline $\mathrm{Mn}$ & 0.0 & 0.0 & 0.0 & 0.1 \\
\hline $\mathrm{Fe}$ & 4.8 & 0.7 & 1.1 & 0.4 \\
\hline Total & 64.7 & 1.1 & 43.3 & 1.9 \\
\hline & & & & \\
$\mathrm{H}+\mathrm{C}+\mathrm{O}^{*}$ & 35.3 & 1.1 & 56.7 & 1.9 \\
\hline
\end{tabular}

* Difference between total and $100 \%$ is assumed to be the sum of hydrogen, oxygen, and carbon. 
Table 5: Summary of the cement kiln dust (CKD) types with hypothesized precipitation mechanisms.

\begin{tabular}{|c|c|c|c|c|}
\hline CKD & $\begin{array}{c}\text { Distinguishing } \\
\text { Characteristics of Virgin } \\
\text { CKD } \\
\end{array}$ & $\begin{array}{c}\text { Extent of } \\
\text { Carbonation* } \\
\end{array}$ & Figures & Precipitation Mechanisms \\
\hline $\mathrm{AG}^{\ddagger}$ Bypass High & $\begin{array}{l}\text { Lime }(36 \%) \text {, Sylvite }(11 \%) \text {, } \\
\text { water to solid ratio }<1\end{array}$ & $83 \%$ & $8(a-b) \& 9$ & $\begin{array}{l}\text { - Diffusing of } \mathrm{CO}_{2} \text { into } \mathrm{Ca}(\mathrm{OH})_{2} \\
\text { particles causing precipitation in } \\
\text { the particle pores and formation } \\
\text { of a carbonate ring } \\
\text { - } \\
\text { Precipitation by nucleation }\end{array}$ \\
\hline $\mathrm{AG}^{¥}$ Wet & $\begin{array}{l}\text { Calcite }(33 \%), \text { Lime }(22 \%) \text {, } \\
\text { water to solid ratio }<1\end{array}$ & $53 \%$ & 10 & $\begin{array}{l}\text { - } \\
\text { - Drecipitation by nucleation } \\
\text { particles causing precipitation in } \mathrm{CO}_{2} \text { into } \mathrm{Ca}(\mathrm{OH}) 2 \\
\text { the particle pores and formation } \\
\text { of a carbonate ring }\end{array}$ \\
\hline $\mathrm{AG}^{\ddagger}$ Bypass Low & $\begin{array}{l}\text { Lime }(11 \%) \text {, Sylvite }(38 \%) \text {, } \\
\text { water to solid ratio }>1\end{array}$ & $98 \%$ & 11 & 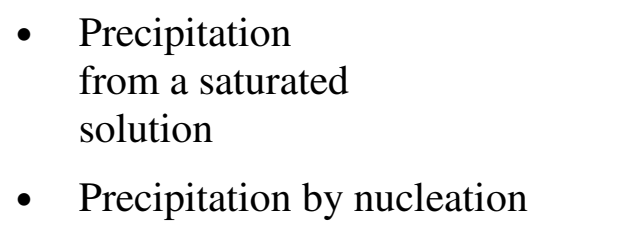 \\
\hline
\end{tabular}

$* \%$ of theoretical extent (Huntzinger et al. 2006a)

${ }^{¥}$ Samples provided by Ash Grove Cement Company 
Table 6: Energy dispersive x-ray elemental microanalysis data (\% dry weight) for locations marked on the Ash Grove Bypass High particles shown in Figure 8.

\begin{tabular}{|c|c|c|c|c|c|c|c|c|c|c|}
\hline Location & \multicolumn{2}{|c|}{ (a) $\mathrm{A}$} & \multicolumn{2}{|c|}{ (a) $\mathrm{B}$} & \multicolumn{2}{|c|}{ (b) $\mathrm{A}$} & \multicolumn{2}{|c|}{ (b) $\mathrm{B}$} & \multicolumn{2}{|c|}{ (b) $\mathrm{C}$} \\
\hline Element & Average & $\begin{array}{l}\text { Standard } \\
\text { Deviation }\end{array}$ & Average & $\begin{array}{l}\text { Standard } \\
\text { Deviation }\end{array}$ & Average & $\begin{array}{l}\text { Standard } \\
\text { Deviation }\end{array}$ & Average & $\begin{array}{l}\text { Standard } \\
\text { Deviation }\end{array}$ & Average & $\begin{array}{l}\text { Standard } \\
\text { Deviation }\end{array}$ \\
\hline $\mathrm{Na}$ & 0.0 & 0.0 & 0.5 & 0.2 & 0.1 & 0.1 & 0.5 & 0.1 & 0.9 & 0.0 \\
\hline $\mathrm{Mg}$ & 0.3 & 0.1 & 1.2 & 0.3 & 0.1 & 0.1 & 0.7 & 0.3 & 1.5 & 0.1 \\
\hline $\mathrm{Al}$ & 0.1 & 0.1 & 0.3 & 0.2 & 0.0 & 0.0 & 0.1 & 0.2 & 11.0 & 0.6 \\
\hline $\mathrm{Si}$ & 0.3 & 0.3 & 0.9 & 0.4 & 0.1 & 0.1 & 0.4 & 0.5 & 16.7 & 0.7 \\
\hline $\mathrm{P}$ & 0.2 & 0.0 & 0.0 & 0.0 & 0.1 & 0.1 & 0.1 & 0.0 & 0.1 & 0.0 \\
\hline$S$ & 0.6 & 0.2 & 0.2 & 0.2 & 0.5 & 0.1 & 0.3 & 0.2 & 0.1 & 0.0 \\
\hline $\mathrm{Cl}$ & 0.7 & 0.2 & 0.3 & 0.1 & 1.8 & 1.7 & 0.4 & 0.1 & 0.2 & 0.2 \\
\hline $\mathrm{K}$ & 0.2 & 0.1 & 1.5 & 0.4 & 2.0 & 1.9 & 1.4 & 0.5 & 2.9 & 0.5 \\
\hline $\mathrm{Ca}$ & 50.6 & 1.5 & 36.0 & 1.1 & 49.8 & 2.0 & 40.5 & 5.4 & 26.8 & 1.5 \\
\hline $\mathrm{Mn}$ & 0.0 & 0.1 & 0.0 & 0.0 & 0.1 & 0.1 & 0.0 & 0.0 & 0.1 & 0.1 \\
\hline $\mathrm{Fe}$ & 0.6 & 0.2 & 0.1 & 0.1 & 0.1 & 0.1 & 0.2 & 0.1 & 2.8 & 0.8 \\
\hline Total & 53.6 & 1.3 & 41.0 & 1.6 & 54.5 & 2.8 & 44.6 & 4.7 & 63.0 & 1.3 \\
\hline $\mathrm{H}+\mathrm{C}+\mathrm{O}^{*}$ & 46.4 & 1.3 & 59.0 & 1.6 & 45.5 & 2.8 & 55.4 & 4.7 & 37.0 & 1.3 \\
\hline
\end{tabular}

* Difference between total and $100 \%$ is assumed to be the sum of hydrogen, oxygen, and carbon. 
Table 7: Energy dispersive x-ray elemental microanalysis data (\% dry weight) for the Ash Grove Bypass High particles shown Figure 9.

\begin{tabular}{|l|r|r|r|r|}
\hline Location & \multicolumn{2}{|c|}{ 8 hr Carbonated } & \multicolumn{2}{|c|}{ 4 d Carbonated } \\
\hline Element & Average & $\begin{array}{l}\text { Standard } \\
\text { Deviation }\end{array}$ & Average & $\begin{array}{r}\text { Standard } \\
\text { Deviation }\end{array}$ \\
\hline $\mathrm{Na}$ & 0.8 & 0.3 & 0.5 & 0.2 \\
\hline $\mathrm{Mg}$ & 0.4 & 0.1 & 1.0 & 0.3 \\
\hline $\mathrm{Al}$ & 0.5 & 0.6 & 0.4 & 0.3 \\
\hline $\mathrm{Si}$ & 1.4 & 1.5 & 1.2 & 0.7 \\
\hline $\mathrm{P}$ & 0.0 & 0.0 & 0.1 & 0.0 \\
\hline $\mathrm{S}$ & 0.0 & 0.0 & 0.1 & 0.0 \\
\hline $\mathrm{Cl}$ & 0.4 & 0.5 & 0.5 & 0.9 \\
\hline $\mathrm{K}$ & 1.0 & 0.6 & 1.9 & 1.2 \\
\hline $\mathrm{Ca}$ & 37.0 & 1.7 & 37.0 & 2.1 \\
\hline $\mathrm{Mn}$ & 0.0 & 0.0 & 0.1 & 0.1 \\
\hline $\mathrm{Fe}$ & 0.2 & 0.2 & 0.4 & 0.5 \\
\hline $\mathrm{Total}$ & 41.7 & 2.7 & 43.4 & 1.9 \\
\hline $\mathrm{H}+\mathrm{C}+\mathrm{O}^{*}$ & 58.3 & 2.7 & 56.6 & 1.9 \\
\hline
\end{tabular}

* Difference between total and $100 \%$ is assumed to be the sum of hydrogen, oxygen, and carbon. 
Table 8: Energy dispersive x-ray elemental microanalysis data (\% dry weight) for the particles shown in Figures $10 \& 11$.

\begin{tabular}{|l|r|r|r|r|}
\hline \multicolumn{1}{|c|}{ Location: } & \multicolumn{2}{|c|}{$\begin{array}{c}\text { AG Wet } \\
\text { (Figure 10) }\end{array}$} & \multicolumn{2}{c|}{$\begin{array}{c}\text { AG Bypass Low } \\
\text { (Figure 11) }\end{array}$} \\
\hline & Average & $\begin{array}{l}\text { Standard } \\
\text { Deviation }\end{array}$ & Average & $\begin{array}{l}\text { Standard } \\
\text { Deviation }\end{array}$ \\
\hline $\mathrm{Na}$ & 0.0 & 0.0 & 0.3 & 0.1 \\
\hline $\mathrm{Mg}$ & 0.3 & 0.1 & 0.2 & 0.0 \\
\hline $\mathrm{Al}$ & 0.1 & 0.1 & 0.2 & 0.1 \\
\hline $\mathrm{Si}$ & 0.1 & 0.1 & 0.6 & 0.3 \\
\hline $\mathrm{P}$ & 0.1 & 0.0 & 0.0 & 0.0 \\
\hline $\mathrm{S}$ & 0.0 & 0.0 & 0.6 & 0.1 \\
\hline $\mathrm{Cl}$ & 0.0 & 0.0 & 1.3 & 0.3 \\
\hline $\mathrm{K}$ & 0.1 & 0.0 & 0.4 & 0.1 \\
\hline $\mathrm{Ca}$ & 40.9 & 1.0 & 38.2 & 3.0 \\
\hline $\mathrm{Mn}$ & 0.2 & 0.1 & 0.0 & 0.0 \\
\hline $\mathrm{Fe}$ & 0.0 & 0.1 & 0.0 & 0.0 \\
\hline Total & 41.7 & 0.9 & 41.7 & 2.4 \\
\hline $\mathrm{H}+\mathrm{C}+\mathrm{O}^{*}$ & 58.3 & 0.9 & 58.3 & 2.4 \\
\hline
\end{tabular}

* Difference between total and $100 \%$ is assumed to be the sum of hydrogen, oxygen, and carbon. 
Table 9: Results from inductively coupled plasma mass spectrometry (ICP-MS) analysis. The extent of carbonation and $\mathrm{pH}$ are also shown.

\begin{tabular}{|l|c|c|c|c|c|r|r|}
\hline \multicolumn{1}{|c|}{ Sample } & $\begin{array}{c}\text { Cr } \\
(\mathbf{p p m})\end{array}$ & $\begin{array}{c}\text { Cu } \\
(\mathbf{p p m})\end{array}$ & $\begin{array}{c}\text { As } \\
(\mathbf{p p m})\end{array}$ & $\begin{array}{c}\text { Cd } \\
(\mathbf{p p m})\end{array}$ & $\begin{array}{c}\text { Pb } \\
(\mathbf{p p m})\end{array}$ & $\begin{array}{c}\text { Extent of } \\
\text { Carbonation* }\end{array}$ & pH \\
\hline $\begin{array}{l}\text { Virgin AG Bypass } \\
\text { High }\end{array}$ & 0.319 & 0.034 & $<0.001$ & 0.002 & 0.039 & -- & 12.7 \\
\hline $\begin{array}{l}\text { Reacted AG Bypass } \\
\text { High }\end{array}$ & 0.099 & 0.032 & $<0.001$ & $<0.001$ & 0.009 & $83 \%$ & 12.4 \\
\hline $\begin{array}{l}\text { Virgin AG Bypass } \\
\text { Low }\end{array}$ & 0.227 & 0.153 & $<0.004$ & $<0.002$ & 0.970 & -- & 12.6 \\
\hline $\begin{array}{l}\text { Reacted AG Bypass } \\
\text { Low }\end{array}$ & 0.112 & 0.098 & $<0.004$ & $<0.002$ & 0.069 & $98 \%$ & 12.4 \\
\hline Virgin AG Wet & 0.139 & 0.044 & 0.001 & 0.0027 & 0.0231 & -- & 12.6 \\
\hline Reacted AG Wet & 0.051 & 0.003 & 0.0015 & 0.0026 & $<0.003$ & $53 \%$ & 10.6 \\
\hline
\end{tabular}

*\% of theoretical extent (Huntzinger et al. 2006a) 
Table 10: Phase assemblage results from PHREEQC equilibrium analysis using $\mathrm{x}$-ray fluorescence spectrometry with X-ray diffraction and thermal gravimetric analysis for starting cement kiln dust compositions. Three results are shown for each cement kiln dust type, using three $\mathrm{CO}_{2}$ concentrations, open and closed $0.035 \% \mathrm{CO}_{2}$ (atmospheric), and $80 \% \mathrm{CO}_{2}$ (concentration used in carbonation experiments).

\begin{tabular}{|c|c|c|c|c|c|c|c|c|c|c|c|c|}
\hline & \multicolumn{4}{|c|}{ Closed Atmospheric $\mathrm{CO}_{2}$} & \multicolumn{4}{|c|}{ Open Atmospheric $\mathrm{CO}_{2}$} & \multicolumn{4}{|c|}{ Open $80 \% \mathrm{CO}_{2}$} \\
\hline AG Bypass High & \multirow[b]{2}{*}{ S.I. } & \multicolumn{3}{|c|}{$\begin{array}{c}\text { Millimoles in } \\
\text { assemblage }\end{array}$} & \multirow[b]{2}{*}{ S.I. } & \multicolumn{3}{|c|}{$\begin{array}{c}\text { Millimoles in } \\
\text { assemblage }\end{array}$} & \multirow[b]{2}{*}{ S.I. } & \multicolumn{3}{|c|}{$\begin{array}{c}\text { Millimoles in } \\
\text { assemblage }\end{array}$} \\
\hline Phase & & Initial & Final & Delta & & Initial & Final & Delta & & Initial & Final & Delta \\
\hline Anhydrite & 0.0 & 2.5 & 1.0 & -1.5 & 0.0 & 5.6 & 1.5 & -4.1 & 0.0 & 2.5 & 0.0 & -2.5 \\
\hline Calcite & 0.0 & 7.0 & 7.0 & 0.0 & 0.0 & 2.0 & 26.0 & 24.0 & 0.0 & 7.0 & 60.3 & 53.4 \\
\hline $\mathrm{CO} 2(\mathrm{~g})$ & -13.1 & 0.0 & 0.0 & 0.0 & -3.5 & 1000.0 & 976.0 & -24.0 & -0.1 & 1000.0 & 943.2 & -56.8 \\
\hline Halite & -4.5 & 1.6 & 0.0 & -1.6 & -3.4 & 4.7 & 0.0 & -4.7 & -4.4 & 1.6 & 0.0 & -1.6 \\
\hline Lime & -10.1 & 48.1 & 0.0 & -48.1 & -19.7 & 15.0 & 0.0 & -15.0 & -23.1 & 48.1 & 0.0 & -48.1 \\
\hline Portlandite & 0.0 & 5.9 & 44.5 & 38.6 & -9.6 & 9.0 & 0.0 & -9.0 & -13.0 & 5.9 & 0.0 & -5.9 \\
\hline Quartz & -0.3 & 16.4 & 0.0 & -16.4 & 0.0 & 6.6 & 6.6 & 0.0 & 0.0 & 16.4 & 16.4 & 0.0 \\
\hline Sylvite & -2.9 & 11.1 & 0.0 & -11.1 & -1.8 & 39.8 & 0.0 & -39.8 & -2.8 & 11.1 & 0.0 & -11.1 \\
\hline AG Bypass Low & \multirow[b]{2}{*}{ S.I. } & \multicolumn{3}{|c|}{$\begin{array}{c}\text { Millimoles in } \\
\text { assemblage }\end{array}$} & \multirow[b]{2}{*}{ S.I. } & \multicolumn{3}{|c|}{$\begin{array}{c}\text { Millimoles in } \\
\text { assemblage }\end{array}$} & & \multicolumn{3}{|c|}{$\begin{array}{c}\text { Millimoles in } \\
\text { assemblage }\end{array}$} \\
\hline Phase & & Initial & Final & Delta & & Initial & Final & Delta & S.I. & Initial & Final & Delta \\
\hline Anhydrite & 0.0 & 5.6 & 2.9 & -2.7 & 0.0 & 5.6 & 1.5 & -4.1 & 0.0 & 5.6 & 1.7 & -3.9 \\
\hline Calcite & 0.0 & 2.0 & 2.0 & 0.0 & 0.0 & 2.0 & 26.0 & 24.0 & 0.0 & 2.0 & 25.4 & 23.4 \\
\hline $\mathrm{CO} 2(\mathrm{~g})$ & -13.1 & 0.0 & 0.0 & 0.0 & -3.5 & 1000.0 & 976.0 & -24.0 & -0.1 & 1000.0 & 973.4 & -26.6 \\
\hline Halite & -3.5 & 4.7 & 0.0 & -4.7 & -3.4 & 4.7 & 0.0 & -4.7 & -3.5 & 4.7 & 0.0 & -4.7 \\
\hline Lime & -10.1 & 15.0 & 0.0 & -15.0 & -19.7 & 15.0 & 0.0 & -15.0 & -23.1 & 15.0 & 0.0 & -15.0 \\
\hline Portlandite & 0.0 & 9.0 & 19.2 & 10.3 & -9.6 & 9.0 & 0.0 & -9.0 & -13.0 & 9.0 & 0.0 & -9.0 \\
\hline Quartz & -0.5 & 6.6 & 0.0 & -6.6 & 0.0 & 6.6 & 6.6 & 0.0 & 0.0 & 6.6 & 6.6 & 0.0 \\
\hline Sylvite & -1.8 & 39.8 & 0.0 & -39.8 & -1.8 & 39.8 & 0.0 & -39.8 & -1.8 & 39.8 & 0.0 & -39.8 \\
\hline AG Wet & \multirow[b]{2}{*}{ S.I. } & \multicolumn{3}{|c|}{$\begin{array}{c}\text { Millimoles in } \\
\text { assemblage }\end{array}$} & \multirow[b]{2}{*}{ S.I. } & \multicolumn{3}{|c|}{$\begin{array}{l}\text { Millimoles in } \\
\text { assemblage }\end{array}$} & & \multicolumn{3}{|c|}{$\begin{array}{c}\text { Millimoles in } \\
\text { assemblage }\end{array}$} \\
\hline Phase & & Initial & Final & Delta & & Initial & Final & Delta & S.I. & Initial & Final & Delta \\
\hline Anhydrite & 0.0 & 7.2 & 5.6 & -1.6 & 0.0 & 7.2 & 2.2 & -4.9 & 0.0 & 7.2 & 2.8 & -4.3 \\
\hline Calcite & 0.0 & 24.4 & 24.4 & 0.0 & 0.0 & 24.4 & 59.7 & 35.3 & 0.0 & 24.4 & 58.9 & 34.6 \\
\hline $\mathrm{CO} 2(\mathrm{~g})$ & -13.1 & 0.0 & 0.0 & 0.0 & -3.5 & 1000.0 & 964.6 & -35.4 & -0.1 & 1000.0 & 961.8 & -38.2 \\
\hline $\mathrm{K} 2 \mathrm{O}$ & -62.9 & 3.2 & 0.0 & -3.2 & -71.6 & 3.2 & 0.0 & -3.2 & -75.1 & 3.2 & 0.0 & -3.2 \\
\hline Lime & -10.1 & 29.4 & 0.0 & -29.4 & -19.7 & 29.4 & 0.0 & -29.4 & -23.1 & 29.4 & 0.0 & -29.4 \\
\hline $\mathrm{Na} 2 \mathrm{O}$ & -47.7 & 0.6 & 0.0 & -0.6 & -56.3 & 0.6 & 0.0 & -0.6 & -59.7 & 0.6 & 0.0 & -0.6 \\
\hline Portlandite & 0.0 & 2.2 & 26.2 & 24.0 & -9.6 & 2.2 & 0.0 & -2.2 & -13.0 & 2.2 & 0.0 & -2.2 \\
\hline Quartz & -0.3 & 15.8 & 0.0 & -15.8 & 0.0 & 15.8 & 15.7 & 0.0 & 0.0 & 15.8 & 15.7 & 0.0 \\
\hline
\end{tabular}

S.I. = Saturation Index 
Table 11: Elemental concentrations calculated by PHREEQC compared with the results from inductively coupled plasma optical emission spectrometry (ICP-OES) using ) using $\mathrm{X}$-ray fluorescence spectrometry with $\mathrm{x}$-ray diffraction and thermal gravimetric analysis for the starting composition. Three PHREEQC results are shown for each cement kiln dust type, using three $\mathrm{CO}_{2}$ concentrations: open and closed $0.035 \% \mathrm{CO}_{2}$ (atmospheric), and open $80 \% \mathrm{CO}_{2}$ (concentration used in carbonation experiments).

\begin{tabular}{|c|c|c|c|c|c|}
\hline \multirow{2}{*}{$\begin{array}{l}\text { Estimation Method } \\
\mathrm{CO}_{2} \text { Atmosphere* }\end{array}$} & \multicolumn{3}{|c|}{ PHREEQC } & \multicolumn{2}{|c|}{ ICP-OES } \\
\hline & $\begin{array}{l}\text { Closed } \\
0.035 \%\end{array}$ & Open $0.035 \%$ & Open $80 \%$ & Virgin & Carbonated \\
\hline \multicolumn{6}{|l|}{ High Free Lime } \\
\hline $\mathrm{C}(\mathrm{ppm})$ & 0 & 4 & 522 & -- & -- \\
\hline $\mathrm{Ca}(\mathrm{ppm})$ & 5700 & 1295 & 1596 & 671 & 249 \\
\hline $\mathrm{Cl}(\mathrm{ppm})$ & 5793 & 5700 & 5704 & -- & -- \\
\hline $\mathrm{K}(\mathrm{ppm})$ & 5607 & 5517 & 5517 & 6678 & 4397 \\
\hline $\mathrm{Na}(\mathrm{ppm})$ & 460 & 453 & 453 & 483 & 227 \\
\hline $\mathrm{S}(\mathrm{ppm})$ & 627 & 1032 & 1032 & 142 & 13 \\
\hline $\mathrm{Si}(\mathrm{ppm})$ & 5335 & 2 & 2 & -- & - \\
\hline $\mathrm{pH}$ & 12.16 & 7.64 & 5.90 & 12.7 & 12.4 \\
\hline Total alkalinity (eq/kg) & $2.46 \mathrm{E}-01$ & $3.43 \mathrm{E}-04$ & $1.54 \mathrm{E}-02$ & -- & -- \\
\hline Total CO2 $(\mathrm{mol} / \mathrm{kg})$ & 7.34E-06 & $3.45 \mathrm{E}-04$ & $4.35 \mathrm{E}-02$ & -- & -- \\
\hline \multicolumn{6}{|l|}{ Low Free Lime } \\
\hline $\mathrm{C}(\mathrm{ppm})$ & 0 & 4 & 134 & -- & -- \\
\hline $\mathrm{Ca}(\mathrm{ppm})$ & 3843 & 2104 & 2184 & 1925 & 1463 \\
\hline $\mathrm{Cl}(\mathrm{ppm})$ & 20221 & 20086 & 20086 & -- & -- \\
\hline $\mathrm{K}(\mathrm{ppm})$ & 19957 & 19828 & 19828 & 24015 & 16283 \\
\hline $\mathrm{Na}(\mathrm{ppm})$ & 1378 & 1369 & 1369 & 1573 & 1041 \\
\hline $\mathrm{S}(\mathrm{ppm})$ & 1123 & 1680 & 1643 & 1612 & 1395 \\
\hline $\mathrm{Si}$ (ppm) & 2129 & 2 & 2 & -- & -- \\
\hline $\mathrm{pH}$ & 12.27 & 7.58 & 6.25 & 12.6 & 12.4 \\
\hline Total alkalinity $(\mathrm{eq} / \mathrm{kg})$ & $1.221 \mathrm{E}-01$ & $3.362 \mathrm{E}-04$ & $6.665 \mathrm{E}-03$ & -- & -- \\
\hline Total CO2 (mol/kg) & 7.754E-06 & 3.364E-04 & $1.115 \mathrm{E}-02$ & -- & -- \\
\hline \multicolumn{6}{|l|}{ AG Wet } \\
\hline $\mathrm{C}(\mathrm{ppm})$ & 0 & 6 & 612 & -- & -- \\
\hline $\mathrm{Ca}(\mathrm{ppm})$ & 3947 & 654 & 750 & 879 & 564 \\
\hline $\mathrm{K}(\mathrm{ppm})$ & 3525 & 3481 & 3482 & 2157 & 1337 \\
\hline $\mathrm{Na}(\mathrm{ppm})$ & 394 & 389 & 389 & 222 & 90 \\
\hline $\mathrm{S}(\mathrm{ppm})$ & 731 & 2214 & 1943 & 827 & 958 \\
\hline $\mathrm{Si}(\mathrm{ppm})$ & 5590 & 2 & 2 & -- & -- \\
\hline $\mathrm{pH}$ & 12.23 & 7.83 & 6.10 & 12.6 & 10.6 \\
\hline Total alkalinity (eq/kg) & $2.590 \mathrm{E}-01$ & $4.948 \mathrm{E}-04$ & $2.224 \mathrm{E}-02$ & -- & -- \\
\hline Total CO2 $(\mathrm{mol} / \mathrm{kg})$ & 7.544E-06 & 4.944E-04 & $5.097 \mathrm{E}-02$ & -- & -- \\
\hline
\end{tabular}

